\title{
Neurodevelopmental alcohol exposure elicits long-term changes to gene expression that alter distinct molecular pathways dependent on timing of exposure
}

Morgan L Kleiber, Katarzyna Mantha, Randa L Stringer and Shiva M Singh ${ }^{*}$

\begin{abstract}
Background: Maternal alcohol consumption is known to adversely affect fetal neurodevelopment. While it is known that alcohol dose and timing play a role in the cognitive and behavioral changes associated with prenatal alcohol exposure, it is unclear what developmental processes are disrupted that may lead to these phenotypes.

Methods: Mice ( $\mathrm{n}=6$ per treatment per developmental time) were exposed to two acute doses of alcohol ( $5 \mathrm{~g} / \mathrm{kg}$ ) at neurodevelopmental times representing the human first, second, or third trimester equivalent. Mice were reared to adulthood and changes to their adult brain transcriptome were assessed using expression arrays. These were then categorized based on Gene Ontology annotations, canonical pathway associations, and relationships to interacting molecules.

Results: The results suggest that ethanol disrupts biological processes that are actively occurring at the time of exposure. These include cell proliferation during trimester one, cell migration and differentiation during trimester two, and cellular communication and neurotransmission during trimester three. Further, although ethanol altered a distinct set of genes depending on developmental timing, many of these show interrelatedness and can be associated with one another via 'hub' molecules and pathways such as those related to huntingtin and brain-derived neurotrophic factor.

Conclusions: These changes to brain gene expression represent a 'molecular footprint' of neurodevelopmental alcohol exposure that is long-lasting and correlates with active processes disrupted at the time of exposure. This study provides further support that there is no neurodevelopmental time when alcohol cannot adversely affect the developing brain.
\end{abstract}

Keywords: Fetal alcohol spectrum disorders, Development, Brain, Mouse, Gene expression, Expression array

\section{Background}

Maternal ethanol consumption is known to be detrimental to the carefully-organized molecular processes that guide the neurodevelopment of a fetus. It can lead to a variety of physiological and neurological consequences, collectively known as fetal alcohol spectrum disorders (FASDs) [1-3]. Given that approximately one-half of North American women drink at least occasionally, and that half of all

\footnotetext{
* Correspondence: ssingh@uwo.ca

Molecular Genetics Unit, Department of Biology, University of Western Ontario, London, Ontario N6A 5B7, Canada
}

pregnancies are unplanned, it is likely that at least onequarter of all infants born have been exposed to alcohol at least once during gestation [4], making FASD one of the most common and financially costly sources of developmental disability [5-7]. Further, the effects of prenatal alcohol exposure are long-lasting, drastically affecting the developmental and socioeconomic trajectory of the affected individual [8-10]. Our understanding of how neurodevelopmental alcohol exposure can cause these persistent changes in cognitive function, however, is not understood.

Most of the existing literature on FASD has focused on using animal models to understand the immediate
C Bïomed Central

(c) 2013 Kleiber et al.; licensee BioMed Central Ltd. This is an Open Access article distributed under the terms of the Creative Commons Attribution License (http://creativecommons.org/licenses/by/2.0), which permits unrestricted use, distribution, and reproduction in any medium, provided the original work is properly cited. 
effects of developmental ethanol exposure. These studies have shown that ethanol exposure is able to alter gene expression in the developing brain, both immediately following acute high-dose exposure [11-13] as well as in the adult brain following moderate chronic neurodevelopmental exposure [14,15] and binge exposures [16,17], altering genes involved in cell survival, cell signaling, and neurotransmission. However, these studies often use variable treatment models with regard to dosage, timing, and assessment of a given molecular or behavioral phenotype, making comparisons between studies difficult. Also, while these studies often report acute and short-term changes to the transcriptome, it is less clear what the long-term consequences of ethanol exposure are and how exposure may alter neural function across the lifetime of the exposed individual.

Previously, we have shown that voluntary maternal ethanol consumption during gestation leads to changes in brain gene expression in exposed adult mice [15]. While the results identified a number of genes that have previously been implicated in FASD-relevant neurobehavioral phenotypes such as cognitive function, anxiety, attention deficit hyperactivity disorder, and mood disorders, the effects of this moderate exposure throughout pregnancy were subtle, making the identification of statistically significant gene changes, and therefore affected pathways, challenging. Further, this voluntary maternal consumption paradigm (consisting of continuous maternal free access to a $10 \%$ ethanol solution throughout gestation) did not allow us to assess the effect of timing of ethanol exposure on the specific biological processes that were occurring at each neurodevelopmental stage. The results do, however, suggest that maternal alcohol consumption is able to leave a complex 'footprint' that remains long after the cessation of alcohol exposure. These changes are persistent and alter molecular pathways important for adult brain function.

Recently, we have evaluated the effects of a binge-like ethanol exposure in a C57BL/6J (B6) mouse model at three specific gestational or postnatal times roughly corresponding to the occurrence of human trimesters one, two, and three [18-20]. This treatment paradigm resulted in offspring showing many phenotypes relevant to FASD including delay of achievement of basic neuromuscular coordination and reflexes, altered activity and anxietyrelated traits, and spatial learning and memory impairments [21]. Interestingly, although the treatments generally produced similar sets of behavioral changes, a closer examination of each specific phenotype revealed that their occurrence and severity were dependent on the developmental timing of the ethanol exposure. This follows recent studies that have started to evaluate the relationship between exposure at various developmental stages and the resulting phenotypic effects. Behaviorally, it has been found that early trimester-three equivalent exposure was more detrimental to adult trace conditioning than later treatments [22]. Also, a recent study by Lipinski et al. [23] revealed that small changes in exposure during early gestation led to differences in craniofacial morphology in a mouse model of fetal alcohol syndrome (FAS) that, interestingly, correlated with specific brain abnormalities.

This study seeks to extend our previous studies evaluating the long-term consequences of neurodevelopmental alcohol exposure. Specifically, we investigate the timing effects of a consistent dose of ethanol administered at the mouse equivalent of the first, second, or third human trimesters. Our objective is to identify the long-term effects of disrupting neurobiological processes occurring at these three times by evaluating the residual pattern of altered genes, pathways, and gene networks within the adult brain. We show that there are some common pathways that are affected by ethanol exposure, regardless of developmental timing. Also, our data suggest that ethanol exposure tends to disrupt critical molecular processes that are known to be actively occurring at each specific developmental time. These processes remain altered at least into adulthood, when the behavioral phenotypes that may be driven by these molecular alterations can affect an individual's overall socioeconomic success $[3,9,24]$. It is hoped that this study provides a broad analysis of the long-term molecular effects of developmental ethanol exposure, and that it allows for a comparison of the susceptibility of particular processes at three critical neurodevelopment times to alcohol teratogenicity.

\section{Methods}

\section{Animals and ethanol treatment}

All animal protocols were approved by the Animal Use Subcommittee at the University of Western Ontario (London, ON, Canada) and complied with the ethical standards established by the Canadian Council on Animal Care. C57BL/6J (B6) mice were originally obtained from Jackson Laboratories (Bar Harbor, ME, USA) and subsequently maintained at the Health Sciences Animal Care Facility at the University of Western Ontario. Males and females were housed in same-sex colonies with ad libitum access to water and food. Cages and bedding, including access to environmental enrichment, were standardized between cages. Colonies were kept in a controlled environment on a 14/10-h light/dark cycle at a temperature of $21^{\circ} \mathrm{C}$ to $24^{\circ} \mathrm{C}$ with $40 \%$ to $60 \%$ humidity.

Female mice of approximately 8 weeks of age were time-mated overnight with 8 - to 12 -week old males. During gestation, dams were housed individually in standard cages. Six treatment times were selected to approximate ethanol exposure occurring at the human first, second, and third trimesters: dam treatment at embryonic days (E) 8 and 11 (human trimester one equivalent), E14 and 
16 (human second trimester equivalent), and pup treatment on postnatal days (P) 4 and 7 (human third trimester equivalent) $[19,25]$. Each mouse (dam or pup) was treated on two treatment. To model punctuated highblood alcohol (binge-like) exposure at these specific stages, dams (trimesters one and two) or pups (trimester three) were injected subcutaneously with $2.5 \mathrm{~g} / \mathrm{kg}$ of ethanol in $0.15 \mathrm{M}$ saline at $0 \mathrm{~h}$ and $2 \mathrm{~h}$. This method has been previously reported and induces a peak blood alcohol level of over $0.3 \mathrm{~g} / \mathrm{dl}$ for 4 to $5 \mathrm{~h}$ following injection, and is sufficient to induce neuronal apoptosis and result in FASD-related behaviors [21,26,27]. Control dams and pups were injected with saline alone, and where possible, mice were matched across treatments for weight. Pups were weaned into same-sex colonies of two to four mice at P21 to P25 and raised under standard housing conditions.

\section{RNA isolation and microarray hybridization}

At P60, male offspring from the above treatment models were sacrificed by carbon dioxide asphyxiation and whole brain tissue (all structures including the olfactory bulb to the medulla) was isolated, snap-frozen in liquid nitrogen, then stored at $-80^{\circ} \mathrm{C}$ until RNA isolation. Total RNA was isolated using Trizol $^{\circledR}$ (Invitrogen, Carlsbad, CA, USA) according to the manufacturer's instructions and cleaned using RNeasy Mini kit (QIAGEN, Valencia, CA, USA). The quality and quantity of RNA was assessed using the Agilent 2100 Bioanalyzer (Agilent Technologies Inc., Palo Alto, CA, USA) and a NanoDrop ND-1000 spectrophotometer (Thermo Fisher Scientific Inc., Wilmington, DE, USA). Each biological replicate consisted of equal quantities of RNA from three non-littermate males pooled to reduce litter effects. Two biological replicates per treatment group were used ( $n=12$ mice per treatment time). All RNA labeling and hybridization steps were performed at the London Regional Genomics Centre (Robarts Research Institute, London, ON, Canada). Briefly, single-stranded complementary DNA (sscDNA) was synthesized using 200 ng of total RNA using the Ambion WT Expression Kit for Affymetrix GeneChip Whole Transcript WT Expression Arrays (Applied Biosystems, Carlsbad, CA, USA) and the Affymetrix GeneChip WT Terminal Labeling kit and hybridization manual (Affymetrix, Santa Clara, CA, USA). First-cycle cDNA was transcribed in vitro to cRNA, and used to synthesize $5.5 \mu \mathrm{g}$ of sscDNA that was subsequently end-labeled and hybridized for $16 \mathrm{~h}$ at $45^{\circ} \mathrm{C}$ to Affymetrix Mouse Gene 1.0 ST arrays. For each treatment time, arrays (two control and two ethanol-exposed) were used for a total of 12 arrays. Liquid-handling steps were performed by a GeneChip Fluidics Station 450 and arrays were scanned using the GeneChip Scanner 3000 using Command Console v1.1 (Affymetrix, Santa Clara, CA, USA).

\section{Microarray data analysis}

Probe level (.CEL) data were generated using Affymetrix Command Console v1.1 and probes were summarized to gene-level data using Partek Genomics Suite software v.6.6 (Partek Inc., St. Louis, MO, USA). Array data from all treatment times (12 arrays) were included in a single analysis. Data were background corrected, quantilenormalized, summarized using the GeneChip-Robust Multiarray Averaging (GC-RMA) algorithm to take into account probe GC-content [28], and $\log _{2}$-transformed. The Partek Suite was also used to determine gene-level ANOVA $P$ values and fold changes. Given that prenatal ethanol exposure produces mostly subtle long-term changes in gene expression [15], genes meeting the criteria of a 1.2-fold change with a FDR-corrected $P$ value $<0.05$ were considered for further analysis. Unannotated genes and standards were removed from the gene lists used for clustering and pathway analyses. These significant genes were subjected to hierarchical clustering analysis using Euclidean distance and average linkage to assess the consistency across replicates and to evaluate the general trends in changes to gene expression across each treatment. All data files from the array experiments have been deposited in the National Center for Biotechnology Information Gene Expression Omnibus and can be found under the accessions GSE34469 and GSE34549. Complete lists of differentially expressed genes identified for each of the three treatments are given in Additional file 1: Table S1.

\section{Gene ontology and gene network analysis}

To evaluate genes and processes that may be involved in a general ethanol response regardless of developmental timing, a list containing genes that were differentially expressed across multiple treatments was generated. This list was analyzed using the functional annotation and clustering software tool available through the online Database for Annotation, Visualization and Integrated Discovery (DAVID) Bioinformatics Resources v.6.7 [29,30]. Gene Ontology (GO) terms and Swiss-Prot and Protein Information Resource (SP PIR) keywords were used to cluster genes. Non-redundant terms with $P<0.05$ were reported.

To identify over-represented GO terms associated with genes showing altered expression for individual trimester treatments, Ingenuity Pathway Analysis v.9 (IPA) (Ingenuity Systems, Redwood, CA, USA; www.ingenuity.com) was used to cluster genes based on biological function. Average fold-change and $P$ values of each gene were included in the analysis. As most genes identified were downregulated, both up- and downregulated genes were assessed concurrently. Redundant GO categories (those containing the same molecules with closely related functions) were removed. Biological functions annotations with a $P<0.05$ were included. IPA was also used to generate gene networks between genes possessing annotated functional relationships with 
other genes, proteins, and molecules. Networks showing a cutoff significance score of 3 or more $(P<0.001)$ were reported.

\section{Quantitative RT-PCR}

RNA extracts not used for array hybridization were used to confirm the expression of selected genes by real-time RT-PCR. Complementary DNA (cDNA) was synthesized using $2 \mu \mathrm{g}$ of total brain RNA using a High-Capacity cDNA Reverse Transcription kit (Applied Biosystems, Foster City, CA, USA) according to the manufacturer's protocol. Gene-specific TaqMan ${ }^{\circledR}$ Assay Reagents and TaqMan Gene Expression Assay products were used on a StepOne Real Time PCR System (all Applied Biosystems, Foster City, CA, USA). Primers and FAM-labeled probes for Tnfrsf19 (E8/11) Cdkn1a, Manf, Htr5a (E14/16), Cnr1, and Grin $2 b$ (P4/7) were obtained from Applied Biosystems Inventoried Assays and used as per the manufacturer's instructions. These genes were selected on the basis of their functional relevance to cell stress and survival pathways (Cdkn1a, Tnfrsf19) or neurological function (Manf, Htr5a, Grin2b, Cnr1). Reactions were multiplexed with Gapdh using gene-specific primers and a VIC-labeled probe. Reactions were run following a standard ramp speed protocol using $10 \mu$ Lvolumes. PCR cycling consisted of a $10 \mathrm{~min}$ initiation at $95^{\circ} \mathrm{C}$, followed by 40 cycles consisting of a $15 \mathrm{~s}$ denaturation at $95^{\circ} \mathrm{C}$ and an anneal and extension at $60^{\circ} \mathrm{C}$ for $60 \mathrm{~s}$. All experiments included six biological replicates per treatment and three technical replicates per sample. Relative expression was calculated according to the comparative $C_{\mathrm{T}}$ method [31] using StepOne $^{\mathrm{TM}}$ v2.0 software (Applied Biosystems) and analyzed using SPSS v.16 (SPSS Inc., Chicago, IL, USA). All PCR data are reported as mean \pm SEM relative expression values. Significant differences were assessed using a student's $t$-test using SPSS v.16 (SPSS Inc, Chicago, IL, USA).

\section{Results}

Neurodevelopmental timing of ethanol exposure dictates the pattern of gene expression changes in the adult brain We first assessed the overall patterns of gene expression in three groups of adult (P60) mice subjected to bingelike ethanol exposures at E8 and 11 (E8/11) (first human trimester equivalent), E14 and 16(E14/16) (second human trimester equivalent), or P4 and 7 (P4/7) (third human trimester equivalent) by performing a hierarchical clustering analysis of the signal ratios of all arrays. The heat map representing array clustering based on normalized probe intensity showed that the control chips cluster closely despite some inter-individual variation, as expected (Figure 1). The results also showed that the pattern of adult brain gene expression following ethanol exposure during the three developmental times was variable and dependent on the timing of the treatment, as evidenced by the distinct branches for each treatment paradigm. Neurodevelopmental ethanol exposure at E8/11, E14/16, and $\mathrm{P} 4 / 7$ resulted in the altered expression of 195 genes, 231 genes, and 336 genes, respectively (fold change $>1.2$, FDR-corrected $P<0.05)$ in the adult brain. These changes ranged from a +3.3 -fold increase from matched controls (Proline rich protein 2 following P4/7 treatment) to -3.2fold decrease (Stomatin (Epb7.2)-like 3 following E14/16 treatment). Further, the distribution of up- and downregulated genes were not equal with only 61 genes (31\%), 54 genes (23\%), and 15 genes (4\%) showing increased expression as compared to controls following ethanol treatment at E8/11, E14/16, and P4/7, respectively. There was also little overlap between genes altered across the three treatment times (Figure 2) with $82 \%, 88 \%$, and $89 \%$ of the genes affected specific to a single one treatment time. Also, 48 genes were found to be altered by at least two treatments, with four (Gmze, Hsf1, Rhog, Trdn) altered by ethanol exposure by all three (Table 1, Figure 2). Full gene lists can be found in Additional file 1: Table S1.

\section{Real-time PCR validation of array results}

We chose to confirm the changes in expression of five genes altered by ethanol exposure identified by the array experiments using real-time PCR to validate our array results. The real-time results and microarray fold-changes for the five genes are shown in Figure 3. For E8/11, the downregulation of tumor necrosis factor receptor superfamily, member 19 (Tnfrsf19) was confirmed $(P=0.024)$. We were also able to confirm the downregulation of cyclindependent kinase inhibitor 1A (P21) (Cdkn1a) $(P=0.019)$ and mesencephalic astrocyte-derived neurotrophic factor (Manf) $(P=0.024)$, both shown to be differentially expressed following ethanol treatment at E14/16. We were not able to confirm the downregulation of Htr5a by quantitative PCR $(P>0.05)$. We also evaluated the expression of cannabinoid receptor 1 (brain) (Cnrl) and glutamate receptor, ionotropic, NMDA2B (epsilon 2) (Grin2b), both downregulated following ethanol treatment at P4/7. Realtime results confirmed the array results with both $\mathrm{Cnr} 1$ $(P=0.0042)$ and Grin $2 b(P=0.014)$ genes showing statistically significant downregulation.

\section{Functional annotation analysis of genes affected by ethanol treatment}

Functional clustering analysis was performed using the 48 genes altered by more than one treatment paradigm (Table 1) to assess potentially common processes affected by neurodevelopmental alcohol exposure, regardless of timing. Genes were evaluated together in a single analysis using the Database for Annotation, Visualization and Integrated Discovery (DAVID ) v6.7 [29,30], which returned three significant functional annotation clusters. Most significant was the GO biological process (BP) 


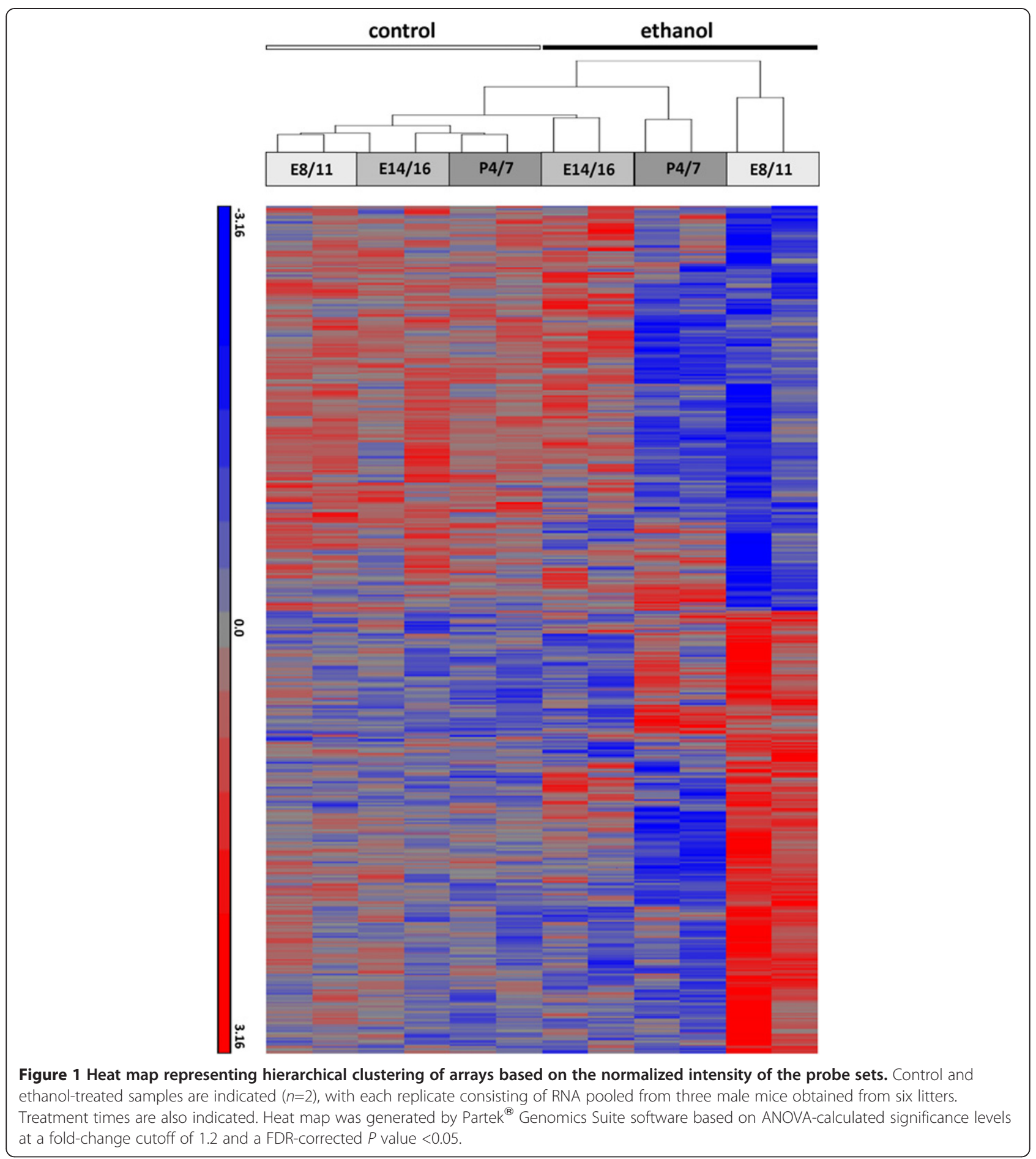

term 'cell death' $(P=0.0047)$, which included the genes Egln3, Gzme, Map3k1, Mef2d, Pglyrp1, and Sra1. Also significant were genes associated with the SP PIR keyword 'methylation' $(P=0.011)$, consisting of Hist $1 \mathrm{~h} 2 \mathrm{bm}$, Hist $1 h 3 c, U b c$, and Rhog, and the GO BP term 'positive regulation of gene expression' $(P=0.021)$, consisting of Iltifb, Ntf3, Rhog, Sra1, and Tnfsf13b.
Gene enrichment analysis identifies that alterations to genetic processes caused by neurodevelopmental ethanol are exposure-stage dependent

The gene lists generated from each individual treatment model were subjected to GO analysis to evaluate overrepresented molecular functions and biological processes using the 'core analysis' function within the IPA software 


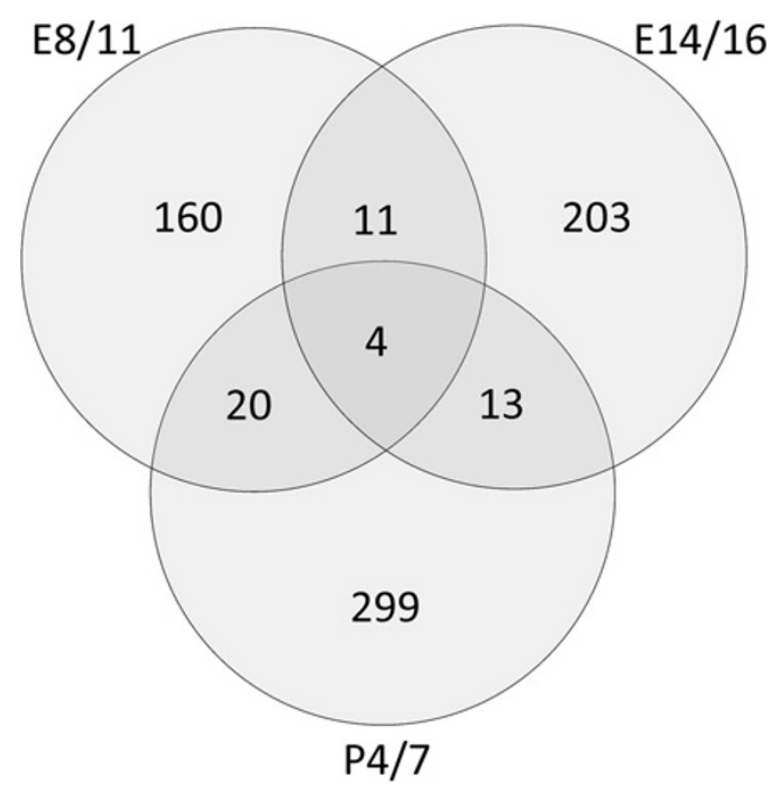

Figure 2 Venn diagram indicating the number of differentially expressed genes identified by each treatment paradigm (E8/11, E14/16, P4/7), including the number of genes that overlapped between multiple treatments.

v.9 (Ingenuity Systems, Redwood, CA, USA). Results of this analysis indicating the most significant nonredundant GO categories and 'functions annotations' are shown in Table 2 . The GO terms significantly associated with genes disrupted by ethanol treatment at E8/11 suggested a disruption in processes associated with cellular organization, cellular development, and cell death. The functions annotations associated with these GO categories indicate that mice exposed to ethanol at E8/11 may have deficits related to quantity of neurons and abnormal axon development, potentially leading to altered synaptic function. Interestingly, most of these GO gene enrichment clusters were driven by the presence of neurotrophin 3 (Ntf3).

The significant GO categories identified in adult mice treated with ethanol at E14/16 involved changes to molecules involved in cellular movement, cell death, and cell morphology (Table 2). In contrast to the E8/11 treatment results, which suggested changes to processes involved in cellular survival and proliferation, the functions annotations associated with these GO categories suggested that these mice may show alterations related to neuronal migration and differentiation. These categories appeared to be driven by the altered expression of doublecortin $(D c x)$ and distal-less homeobox 1 and $2(D l x 1, D l \times 2)$. Interestingly, similarly to the cell death annotation in the E8/11 exposure, the 'cell death' function identified in the E14/16 paradigm was also driven by heat shock factor 1 (Hsf1).

The GO categories associated with genes altered by exposure at P4/7 were primarily associated with cell-cell signaling and communication, with alterations to genes whose functions included roles in synaptic formation, transmission, depression, and plasticity. Further, alterations to a number of molecules involved in steroid-mediated cell communication (such as glucocorticoids) were identified, as were changes in genes involved in the gliosis of the hippocampus. These molecular functions suggest that P4/7 ethanol exposure may significantly alter the synaptic function and structure of the adult brain. The molecules that show altered expression following P4/7 exposure support this, with changes to a number of critical neurotransmitterrelated systems such as glutamate (Grik1, Grin2b, Grm4), serotonin (Htr1a), cannabinoids (Cnr1) and ephrins (Ephb1, $E p h b 2)$. Also notable is the altered regulation of apolipoprotein E (Apoe) and propriomelanocortin (Pomc) given their roles in the development and function of the hypothalamicpituitary-adrenal (HPA) axis.

\section{Canonical pathways affected by neurodevelopmental ethanol exposure}

Using Ingenuity ${ }^{\circledR}$ software, we also evaluated the canonical pathways that may be altered as a result of each ethanol treatment. E8/11 exposure was associated with the endoplasmic reticulum stress pathway, xenobiotic metabolism signaling, and, interestingly, glucocorticoid receptor signaling (Table 3). Also significant were phospholipase $\mathrm{C}$ signaling, antiproliferative role of somatostatin receptor 2 , and calcium signaling. The identification of these pathways as significantly altered support that E8/11 exposure may disrupt general systems that have a pleiotropic developmental function. Canonical pathways associated with E14/16 exposure were fatty acid biosynthesis, serotonin receptor signaling, and regulation of actin-based motility by Rho (Table 3 ). These results are consistent with the gene ontology results and support that ethanol exposure during E14/16 may result in the long-term disruption of genes associated with brain cell proliferation and migration processes, as well as some cell-communication functions. Finally, P4/7 exposure was most significantly associated with alterations in molecules involved in glutamate receptor signaling (Table 3), also supporting the P4/7 GO results. Other developmentally-associated Canonical Pathways identified were retinoic acid-mediated apoptosis signaling, ephrin receptor signaling, and, interestingly, Circadian rhythm signaling, which was driven by the alterations to a number of glutamate receptor subunits (Grin $2 b$, Grin3b, Grin2c, and Grin2d). P4/7 ethanol exposure also was associated with changes to the one carbon pool by folate and mTOR signaling pathways.

\section{Network analysis shows common interacting molecules regardless of developmental timing of ethanol exposure} Using the network analysis tool within the Ingenuity ${ }^{\circledR}$ software platform, we predicted interacting molecular networks to further evaluate the broader potential effects 
Table 1 Common genes altered in the adult (P60) brain by different ethanol treatments during neurodevelopment

\begin{tabular}{|c|c|c|c|c|c|c|}
\hline \multirow[t]{2}{*}{ Accession no. } & \multirow{2}{*}{$\begin{array}{l}\text { Gene } \\
\text { symbol }\end{array}$} & \multirow[t]{2}{*}{ Gene name } & \multirow[t]{2}{*}{ Chr. } & \multicolumn{3}{|c|}{ Fold change per treatment time $^{a}$} \\
\hline & & & & E 8/11 & E 14/16 & P 4/7 \\
\hline NM_019816 & Aatf & Apoptosis antagonizing transcription factor & $11 \mathrm{~B} 5$ & -1.20 & ns & -1.32 \\
\hline NM_001190371 & Ankrd29 & Ankyrin repeat domain 29 & $18 \mathrm{~A} 1$ & -1.24 & -1.2 & ns \\
\hline NM_145990 & Cdk5rap2 & CDK5 regulatory subunit associated protein 2 & $4 C 2$ & -1.26 & NS & -1.26 \\
\hline NM_198019 & Cep78 & Centrosomal protein 78 & $19 \mathrm{~A}$ & ns & -1.22 & -1.37 \\
\hline NM_133840 & Clp1 & $\begin{array}{l}\text { Cleavage and polyadenylation factor I subunit, } \\
\text { homolog (S. cerevisiae) }\end{array}$ & $2 \mathrm{D}$ & ns & -1.21 & -1.2 \\
\hline NM_027468 & Cpm & Carboxypeptidase M & $10 \mathrm{D} 2$ & -1.29 & 1.28 & ns \\
\hline NM_001163026 & Dnajc13 & DnaJ (Hsp40) homolog, subfamily C, member 13 & $9 \mathrm{~F} 1$ & ns & 1.24 & -1.21 \\
\hline NM_008929 & Dnajc3 & DnaJ (Hsp40) homolog, subfamily C, member 3 & $14 \mathrm{E} 4$ & -1.21 & ns & -1.38 \\
\hline NM_028133 & Egln3 & EGL nine homolog 3 (C. elegans) & $12 \mathrm{C} 1$ & ns & -1.28 & 1.41 \\
\hline NM_153782 & Fam20a & Family with sequence similarity 20 , member $\mathrm{A}$ & 11 E1 & -1.24 & 1.21 & ns \\
\hline NM_010240 & Ftl1 & Ferritin light chain 1 & 7 B4 & -1.26 & ns & -1.51 \\
\hline NM_001166065 & Gent4 & $\begin{array}{l}\text { Gcnt4 glucosaminyl (N-acetyl) transferase } 4, \\
\text { core } 2 \text { (beta-1,6-N-acetylglucosaminyltransferase) }\end{array}$ & 13 D1 & ns & -1.24 & -1.44 \\
\hline NM_011937 & Gnpda1 & Glucosamine-6-phosphate deaminase 1 & $18 \mathrm{~B} 3$ & -1.21 & ns & -1.48 \\
\hline NM_001013385 & Grm4 & Glutamate receptor, metabotropic 4 & $17 \mathrm{~A} 3$ & -1.33 & ns & -1.38 \\
\hline AK138760 & Gtf3c2 & General transcription factor IIIC, polypeptide 2 , beta & 5 B1 & -1.33 & 1.37 & ns \\
\hline NM_010373 & Gzme & Granzyme E & $14 C 3$ & 1.28 & -1.21 & -1.21 \\
\hline NM_173400 & Haus6 & HAUS augmin-like complex, subunit 6 & $4 \mathrm{C} 4$ & 1.2 & ns & -1.42 \\
\hline NM_175256 & Heg1 & HEG homolog 1 (zebrafish) & $16 \mathrm{~B} 3$ & -1.2 & ns & -1.23 \\
\hline NM_178200 & Hist1h2bm & Histone cluster 1, H2bm & 13 A2-3 & ns & 1.27 & -1.53 \\
\hline NM_175653 & Hist1h3c & Histone cluster $1, \mathrm{H} 3 \mathrm{C}$ & 13 A2-3 & -1.31 & ns & -1.3 \\
\hline NM_001024720 & Hmen 1 & Hemicentin 1 & $1 \mathrm{G} 1$ & 1.2 & ns & -1.28 \\
\hline NM_008296 & Hsf1 & Heat shock factor 1 & 15 D3 & -1.25 & 1.22 & -1.22 \\
\hline NM_054079 & Iltifb & Interleukin 10-related T cell-derived inducible factor beta & $10 \mathrm{D} 2$ & -1.22 & ns & -2.2 \\
\hline NM_201531 & Kenf1 & Potassium voltage-gated channel, subfamily F, member 1 & $12 \mathrm{~A} 1.1$ & -1.31 & -1.21 & ns \\
\hline NM_172871 & Klhl9 & Kelch-like 9 (Drosophila) & $4 C 4$ & ns & -1.21 & -1.31 \\
\hline NM_011945 & Map3k1 & Mitogen-activated protein kinase kinase kinase 1 & $13 \mathrm{D} 2$ & ns & -1.2 & -1.5 \\
\hline BC132343 & Mars2 & Methionine-tRNA synthetase 2 (mitochondrial) & $1 \mathrm{C} 1$ & ns & -1.22 & -1.62 \\
\hline ENSMUST00000001455 & Mef2d & Myocyte enhancer factor 2D & $3 \mathrm{~F} 1$ & -1.21 & ns & -1.26 \\
\hline NR_029580 & Mir194-1 & microRNA 194-1 & 1 & 1.22 & ns & 1.5 \\
\hline NM_028901 & Myo18b & Myosin XVIIIb & $5 \mathrm{~F}$ & 1.26 & -1.26 & ns \\
\hline NM_153578 & Nipa1 & $\begin{array}{l}\text { Non-imprinted in Prader-Willi/Angelman syndrome } 1 \\
\text { homolog (human) }\end{array}$ & $7 C$ & -1.28 & ns & -1.22 \\
\hline NM_001164035 & $\mathrm{Ntf3}$ & Neurotrophin 3 & $6 \mathrm{F3}$ & -1.41 & ns & -1.58 \\
\hline NM_178668 & Pde12 & Phosphodiesterase 12 & $14 \mathrm{~A} 3$ & ns & -1.22 & 1.25 \\
\hline NM_009402 & Pglyrp1 & Peptidoglycan recognition protein 1 & $7 \mathrm{A3}$ & -1.31 & ns & -1.31 \\
\hline NM_001081307 & Ppp1r12b & Protein phosphatase 1, regulatory (inhibitor) subunit $12 \mathrm{~B}$ & $1 \mathrm{~F}$ & ns & -1.21 & -1.29 \\
\hline NM_031499 & Prp2 & Proline rich protein 2 & $6 \mathrm{G} 1$ & 1.68 & ns & 3.3 \\
\hline NM_029614 & $\operatorname{Prss} 23$ & Protease, serine, 23 & $7 \mathrm{E} 1$ & 1.22 & -1.21 & ns \\
\hline NM_019566 & Rhog & Ras homolog gene family, member $\mathrm{G}$ & $7 F 1$ & -1.22 & 1.21 & -1.48 \\
\hline NM_146118 & Slc25a25 & $\begin{array}{l}\text { Solute carrier family } 25 \text { (mitochondrial carrier, } \\
\text { phosphate carrier), member } 25\end{array}$ & $2 \mathrm{~B}$ & -1.21 & ns & -1.35 \\
\hline AF357427 & Snord115 & Small nucleolar RNA, C/D Box 115 cluster & 7 & ns & 1.23 & 1.71 \\
\hline NR_028275 & Snord14e & Small nucleolar RNA, C/D box 14E & 9 & 1.26 & -1.27 & ns \\
\hline
\end{tabular}


Table 1 Common genes altered in the adult (P60) brain by different ethanol treatments during neurodevelopment (Continued)

\begin{tabular}{|c|c|c|c|c|c|c|}
\hline NM_025291 & Sra1 & Steroid receptor RNA activator 1 & $18 \mathrm{~B} 2$ & -1.27 & -1.22 & ns \\
\hline NM_033622 & Tnfsf13b & $\begin{array}{l}\text { Tumor necrosis factor (ligand) superfamily, } \\
\text { member } 13 \mathrm{~b}\end{array}$ & $8 \mathrm{~A} 1$ & 1.21 & ns & -1.23 \\
\hline NM_029726 & Trdn & Triadin & $10 \mathrm{~A} 4$ & 1.27 & -1.61 & -2.21 \\
\hline BC025894 & Ubc & Ubiquitin C & $5 \mathrm{G} 1$ & ns & 1.29 & -1.34 \\
\hline NM_016982 & Vpreb1 & Pre-B lymphocyte gene 1 & $16 \mathrm{~A} 3$ & 1.46 & -1.28 & ns \\
\hline NM_172643 & Zbtb41 & Zinc finger and BTB domain containing 41 homolog & $1 F$ & -1.22 & ns & -1.32 \\
\hline NM_028543 & Zfp763 & Zinc finger protein 763 & $17 \mathrm{~B} 1$ & -1.29 & -1.26 & ns \\
\hline
\end{tabular}

${ }^{\mathrm{a}} \mathrm{E}$, embryonic day; $\mathrm{P}$, postnatal day; ns, not significantly different.

of neurodevelopmental ethanol exposure on the function of adult neurological systems. These analyses suggested that related regulatory and/or effector pathways are associated with ethanol exposure regardless of timing, as well as highlighted some differences that may be associated with timing-specific physiological or behavioral FASDassociated abnormalities.

Analysis of the molecules altered following E8/11 exposure revealed two significant interacting gene networks related to 'Neurological Disease, Psychological Disorders, and Cell Morphology' (NPC) with 18 focus molecules, and 'Organismal Development, Nutritional Disease, and Behavior' (ONB) with 13 focus molecules extracted from the differentially expressed genes (Figures $4 \mathrm{~A}$ and $\mathrm{B}$ ). The NPC network identified a number of molecules related to glutamate signaling although the receptor subunit genes themselves were not differentially expressed. The ONB network indicated the significant interaction of altered genes with the immediate early transcription factor, FBJ murine osteosarcoma viral oncogene homolog (Fos), and, interestingly, three upregulated microRNAs (miRNAs). Given that these two networks contained a number of overlapping genes, the networks were merged to produce a broader view of the molecules that linked the genes altered by E8/11 ethanol exposure (Figure 4C). The merged networks revealed several 'hub' molecules including amyloid beta (A4) precursor protein (App), brain-derived neurotrophic factor $(B d n f)$, Fos, huntingtin $(H t t)$, and tumor protein p53 (Tp53).

Network analysis of genes altered by E14/16 exposure revealed similarities to the E8/11 exposure results, suggesting some common effector molecules may act in response to ethanol exposure regardless of developmental timing. The most significant network functions were 'Cellular Development, Nervous System Development and Function, Behavior' (CNB), with 14 focus molecules, and 'Neurological Disease, Cell Death, and Psychological Disorders' (NCP), also with 14 focus molecules (Figures 5A and B). Again, Htt and Fos appeared as hub molecules within the $\mathrm{CNB}$ network, as well as Jun proto-oncogene

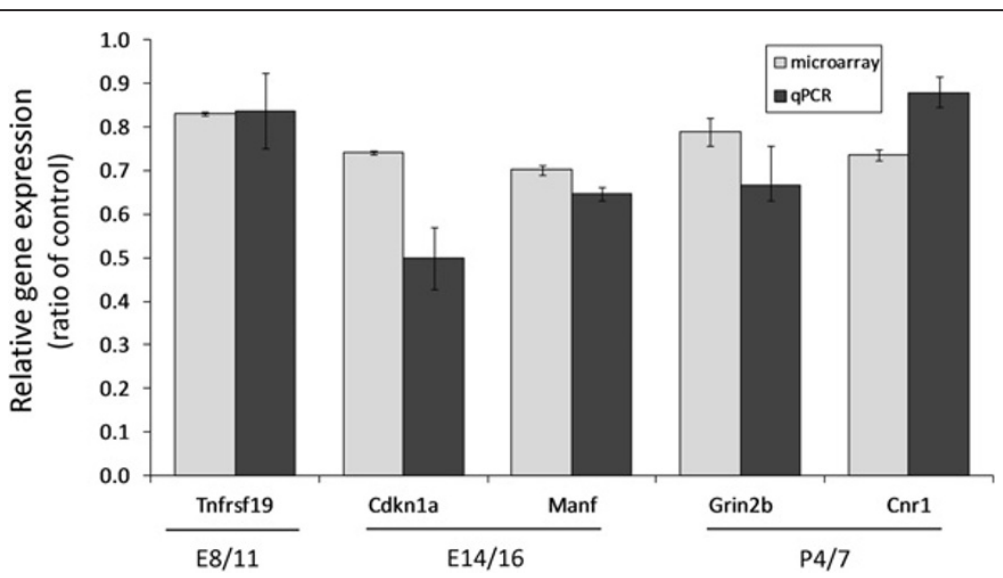

Figure 3 Quantitative PCR confirmation of genes identified as altered by neurodevelopmental ethanol exposure by microarray analysis. Expression values are shown as a ratio of the control value \pm SEM. Microarray values represent the results of ANOVA comparison of two biological replicates, each consisting of the RNA from three non-littermate male mice. Quantitative PCR values were generated using six biological replicates consisting of the RNA from six ethanol-exposed males mice. Significance differences from control values were determined using unpaired $t$-tests. All bars are significantly different from their respective controls $(P<0.05)$. We were unable to confirm the expression of $\operatorname{Htr5a}(P>0.05)$ and therefore this gene is not included in this figure. 
Table 2 Significant gene ontology (GO) categories and molecular functions annotations for genes differentially expressed in the brain of adult (P60) mice neurodevelopmentally exposed to ethanol

\begin{tabular}{|c|c|c|c|c|}
\hline Timing of treatment ${ }^{a}$ & GO category & Functions annotation & $P$ value & Molecules \\
\hline \multirow[t]{6}{*}{ E 8/11 } & Cellular assembly and organization & Extension of axons & 0.0082 & Dclk1, Ntf3, Tnfrsf12a \\
\hline & Protein synthesis & Translation of protein & 0.0025 & Eif2s1, Hspa5 \\
\hline & Cell-to-cell signaling and interaction & Synaptic transmission & 0.0136 & Egr3, Ntf3 \\
\hline & Tissue development & Accumulation of cells & 0.0153 & Cdkn1a, Ntf3 \\
\hline & Cell death & Cell death of sensory neurons & 0.0171 & Hsf1, Ntf3 \\
\hline & Tissue morphology & Quantity of interneurons & 0.0250 & Dclk1, Ntf3 \\
\hline \multirow[t]{6}{*}{ E 14/16 } & Cellular movement & Migration of interneurons & 0.00013 & Dcx, Dlx1, Dlx2 \\
\hline & Tissue development & Development of olfactory bulb & 0.0168 & Dlx2, Nr2e1 \\
\hline & Cellular development & $\begin{array}{l}\text { Differentiation of neuronal } \\
\text { progenitor cells }\end{array}$ & 0.0214 & Dlx1, Dlx2 \\
\hline & Cell death & Cell death of sensory neurons & 0.0238 & Bok, Hsf1 \\
\hline & Neurological disease & Neurodegenerative disorder & 0.0458 & Cav1, Cox1, Dex, Htr6, Pcna \\
\hline & Cell morphology & Shape change of neurons & 0.0473 & Dcx, Hcrt \\
\hline \multirow[t]{7}{*}{ P 4/7 } & Cell-to-cell signaling and interaction & Synaptic transmission & 0.00014 & $\begin{array}{l}\text { Apoe, Chrm1, Cnr1, Ephb2, Grik1, } \\
\text { Grin2b, Htr1a, Nrgn1, Ntf3 }\end{array}$ \\
\hline & Lipid metabolism & Secretion of steroid & 0.0018 & Apoe, Pomc \\
\hline & Cell-to-cell signaling and interaction & Synaptic depression & 0.0133 & Chrm1, Cnr1, Ephb1, Grin2b, Htt \\
\hline & Cell-to-cell signaling and interaction & Plasticity of synapse & 0.0144 & Apoe, Grik1, Grin2b, Htt, Inppl1, Syngap1 \\
\hline & Cell morphology & Formation of cellular protrusions & 0.0329 & $\begin{array}{l}\text { Apoe, Dst, Efna5, Efnb2, Egfr, Ephb1, } \\
\text { Grm4, Htt, Kif23, Nbl1, Ntf3, Ntng2, } \\
\text { Pcdh15, Rhog, Syne1, Syngap1, Wnt3a }\end{array}$ \\
\hline & Cellular development & Proliferation of neuronal cells & 0.0366 & Cnr1, Irx5, Mycn, Nbn, Ntf3, Wnt3a \\
\hline & Neurological disease & Gliosis of hippocampus & 0.0400 & Apoe, Htt \\
\hline
\end{tabular}

${ }^{\mathrm{a}} \mathrm{E}$, embryonic day; $\mathrm{P}$, postnatal day.

(Jun), which, with Fos, forms the early response transcription factor Activator protein 1 (Ap-1). App once again formed a main hub within the NCP network, and Fos and Tp53 appeared within this network similarly to the networks generated from the E8/11 data. Merging of these two networks revealed App, Fos, and $\mathrm{Htt}$ as major hubs once again (Figure 5C). Other major hubs unique to the E14/16 treatment paradigm included notch signaling, Jun, and the cell-cycle transcription factor E2f1.

Network analysis of P4/7 ethanol exposure resulted in gene networks that included some molecules common to the E8/11 and E14/16 analyses, many of which showed altered expression in this treatment model. The two most significant associated network functions were 'Neurological disease, Cell Death, Psychological Disorders' (NCP) with 17 focus molecules and 'Cell Morphology, Cell-To-Cell Signaling and Interaction, Nervous System Development and Function' (CCN) with 14 focus molecules (Figures 6A and B). These network functions support the results of the gene ontology and pathway analysis, suggesting that P4/7 exposure may result in altered cell-cell communication and synaptic function, as well as alterations to intrinsic apoptosis cascade proteins. The NCP network contained $H t t$ as a hub molecule, similar to both E8/11 and E14/16 treatment networks, which was identified as downregulated in the adult brain following P4/7 ethanol treatment. Other hub molecules included glutamate receptor, ionotropic, N-methyl D-aspartate 2B (Grin2b) and the apoptosis enzyme Caspase 3 (Casp3), both of which were also downregulated. The CCN network also contained a number of glutamate receptor subunits with Grin $2 b$ acting as a network hub molecule connecting multiple interacting genes. Other hub molecules included the synaptic protein discs, large homolog 4 (Drosophila) (Dlg4) and retinoic acid receptor, alpha (Rara). The merged networks again suggest $H t t$ as a central hub connecting multiple molecules (Figure $6 \mathrm{C}$ ), as well as the glutamate receptor proteins $\operatorname{Grin} 2 b$ and glutamate receptor, ionotropic, AMPA1 (alpha 1) (Gria1). Neurotrophin 3 (Ntf3), identified as differentially expressed in the adult brain following ethanol treatment at E8/11, was also downregulated by ethanol treatment at $\mathrm{P} 4 / 7$ and appeared as a hub within the merged gene networks, as did apolipoprotein E (Apoe).

\section{Discussion}

The development of the brain is highly orchestrated, coordinated by proper gene expression in response to developmental cues and in response to the environment. It 


\begin{tabular}{|c|c|c|c|}
\hline Timing of treatment ${ }^{a}$ & Ingenuity ${ }^{\circledR}$ canonical pathway & $P$ value & Molecules \\
\hline \multirow[t]{6}{*}{ E 8/11 } & Endoplasmic reticulum stress pathway & 0.00003 & Xbp1, Dnajc3, Eif2s1, Hspa5 \\
\hline & Xenobiotic metabolism signaling & 0.00282 & $\begin{array}{l}\text { Sra1, Ftl, Nras, Map3k13, Camk1g, } \\
\text { Cyp2c19, Ncor2, Mapk11 }\end{array}$ \\
\hline & Glucocorticoid receptor signaling & 0.00501 & $\begin{array}{l}\text { Sra1, Nras, Hpsa1a, Taf5l, Cdkn1a, } \\
\text { Ncor2, Hspa5, Mapk11 }\end{array}$ \\
\hline & Phospholipase C signaling & 0.00741 & $\begin{array}{l}\text { Rhog, Nras, Mef2d, Myl4, Gng13, } \\
\text { Rapgef3, Itga4 }\end{array}$ \\
\hline & Antiproliferative role of somatostatin receptor 2 & 0.0263 & Nras, Cdkn1a, Gng13 \\
\hline & Calcium signaling & 0.0269 & Calr, Mef2d, Trdn, Camk1g, Myl4 \\
\hline \multirow[t]{3}{*}{ E 14/16 } & Fatty acid biosynthesis & 0.00363 & Oxsm, Mcat \\
\hline & Serotonin receptor signaling & 0.00603 & Htr5a, Htr3a, Htr6 \\
\hline & Regulation of actin-based motility by Rho & 0.0145 & Myl9, Rhog, Rnd3, Ppp1r12b \\
\hline \multirow[t]{6}{*}{$P 4 / 7$} & Glutamate receptor signaling & 0.000007 & $\begin{array}{l}\text { Grin2b, Grin3b, Gnb3, Grid1, Grin2c, } \\
\text { Grin2d, Grik3, Grm4, Grik1 }\end{array}$ \\
\hline & Retinoic acid-mediated apoptosis signaling & 0.00055 & Fadd, Casp3, Rarb, Tnfsf10, Rxrb, Irf1 \\
\hline & Ephrin receptor signaling & 0.00224 & $\begin{array}{l}\text { Frin2b, Efnb2, Ephb1, Grin3b, Gnb3, } \\
\text { Itsn1, Grin2c, Efna5, Grin2d, Vegfc, Figf }\end{array}$ \\
\hline & Circadian rhythm signaling & 0.00692 & Grin2b, Grin 3b, Grin2c, ,Grin2d \\
\hline & One carbon pool by folate & 0.00794 & Tyms, Mthfs, Mtr \\
\hline & mTOR signaling & 0.0288 & $\begin{array}{l}\text { Fau, Rhog, Rps10, Rptor, Vegfc, } \\
\text { Figf, Insr, Rpsa }\end{array}$ \\
\hline
\end{tabular}

${ }^{\mathrm{a}} \mathrm{E}$, embryonic day; $\mathrm{P}$, postnatal day.

is also a remarkably vulnerable target for a variety of drugs of abuse, particularly ethanol [32,33]. This vulnerability leads to changes in brain structure and function, resulting in the long-term behavioral and cognitive changes that characterize FASD [1,3,34-36]. The manifestation and severity of specific FASD phenotypes, however, varies widely across individuals prenatally exposed to ethanol for reasons that are not entirely clear. Further, while it is known that developmental ethanol exposure leads to changes in neural molecular architecture, including changes to genome-wide gene expression $[11,12,15])$, how these alterations are initiated, maintained over time, and relate to specific FASD-relevant neurological phenotypes remains unknown. The results included in this report focus on the pattern of long-term changes in brain gene expression in adult B6 mice following ethanol exposure at three neurodevelopmental times corresponding to the approximate human equivalent of trimesters one, two, and three.

In a previous experiment, we have determined that the exposure paradigms used in this study (binge-like treatments at developmental days representing early, mid, and late human gestational neurodevelopmental exposure) result in behavioral phenotypes that are relevant to the abnormalities observed in individuals with FASD [21]. This study seeks to extend these findings by evaluating the genes and their associated pathways that show long-term disruption due to prenatal alcohol exposure. We do acknowledge that the neurodevelopmental timelines in rodents and humans are similar but not identical, particularly the period of synaptogenesis that occurs during the third trimester and extends postnatally in humans but occurs primarily postnatally in mice [19,37]. Also, due to these differences, two of the treatment models (ethanol exposures at E8/11 and E14/ 16) represent maternal treatments whereas mouse pups were administered ethanol in the trimester three model (exposure at $\mathrm{P} 4 / 7$ ). This may result in differences in total blood alcohol levels achieved, which is a caveat of these methods, although there is evidence that ethanol rapidly crosses across the placental barrier and can appear within the embryo within 5 minutes after maternal treatment [38]. Regardless of these potential differences in blood alcohol levels achieved, the results obtained using this mouse model may be an effective means to parse the long-term consequences of fetal alcohol exposure to the developing brain $[18,39]$.

\section{Ethanol-induced long-term changes to gene expression are subtle, multifactorial, and timing-dependent}

The clustering of gene expression signal intensities of the arrays representing the control and ethanol-treated samples (Figure 1) suggested that alcohol exposure during neurodevelopment significantly altered the transcriptome 


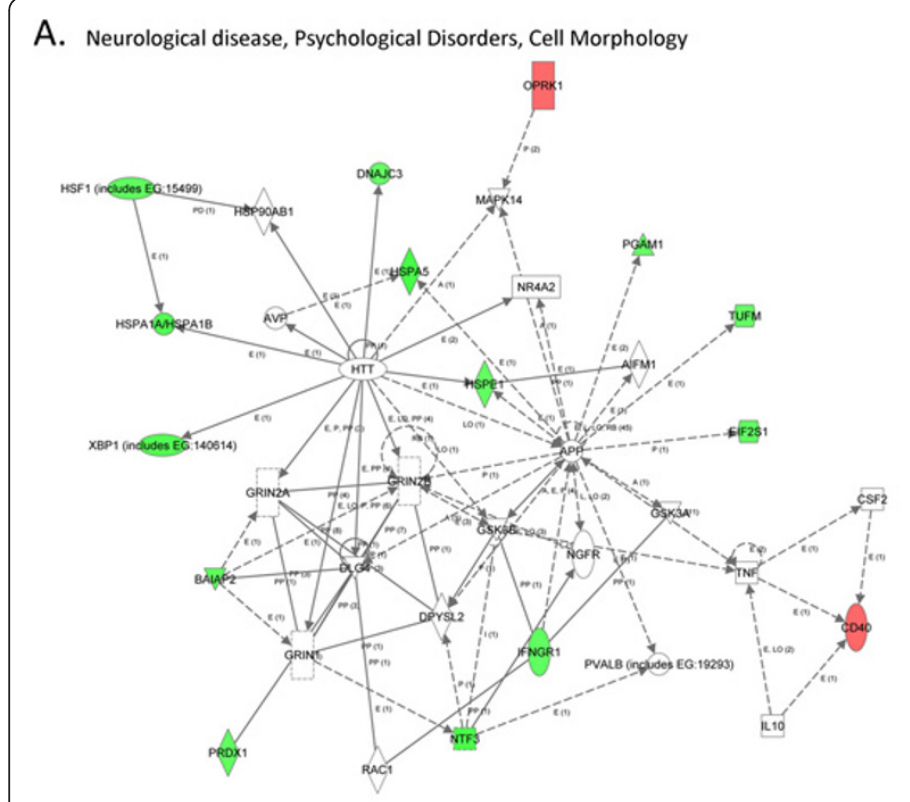

B. Organismal development, Nutritional disease, Behaviour

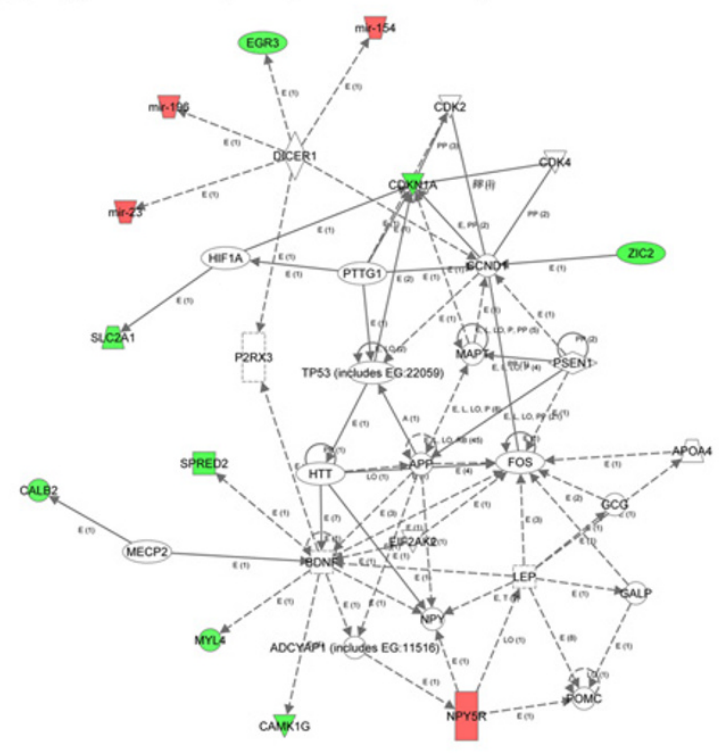

C. Merged networks highlighting hub molecules
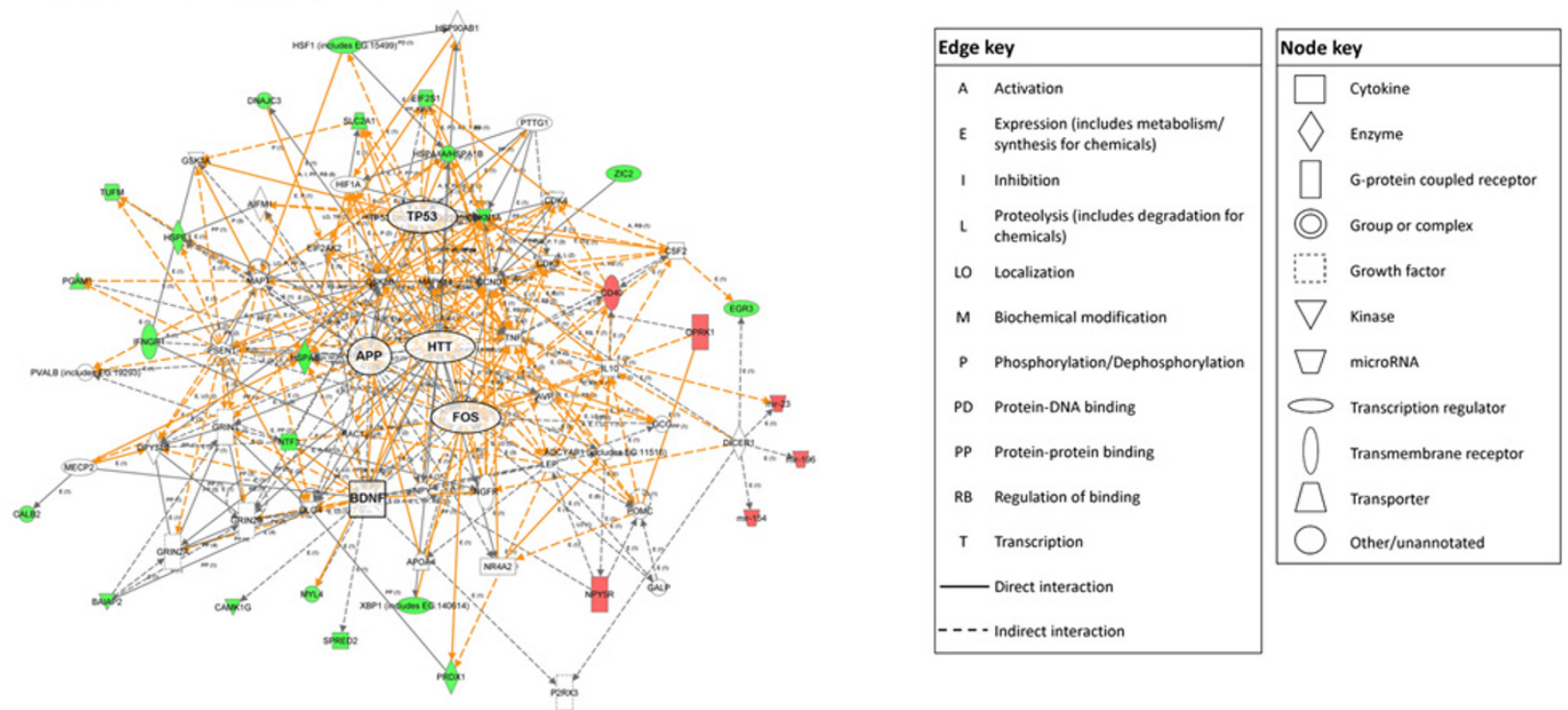

Figure 4 Ingenuity pathway analysis (IPA) network analysis indicating annotated interactions between genes affected in the adult brain by ethanol exposure at E8 and 11. Up- (red) and down- (green) regulated genes are indicated. Significant networks identified, as well as their IPA functional category, are shown in (A) and (B). (C) Merged image of networks shown in (A) and (B) showing the interrelatedness of the genes involved. Centralized 'hub' molecules linking multiple interacting genes are enlarged.

of the adult brain, regardless of timing. Maternal care differences were not assessed in this study and although we and others have previously observed that minor, if any, alterations to maternal care occur following gestational alcohol exposure [40-42], these finding are predominantly based on voluntary maternal consumption paradigms and not binge-like exposures. It is possible, then, that maternal care differences between ethanol-treated and control dams may contribute to the observed gene expression differences.
However, there was very little overlap between the genes identified by each of the ethanol-treatment times (Table 1 , Figure 2), suggesting that a major contributor to the set of genes affected was the timing of exposure. This may be attributed to the considerable changes that occur to the brain transcriptome across development, resulting in a different repertoire of processes on which ethanol may act and leading to a very different footprint of genes that remain altered into adulthood. 
A. Cellular development, Nervous system development, Behaviour

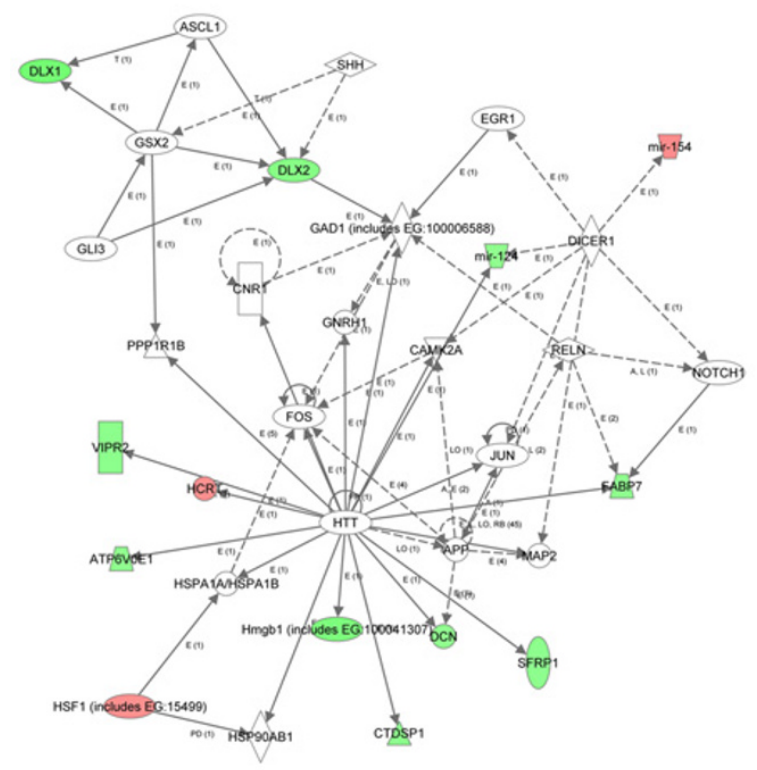

C. Merged networks highlighting central hub molecules

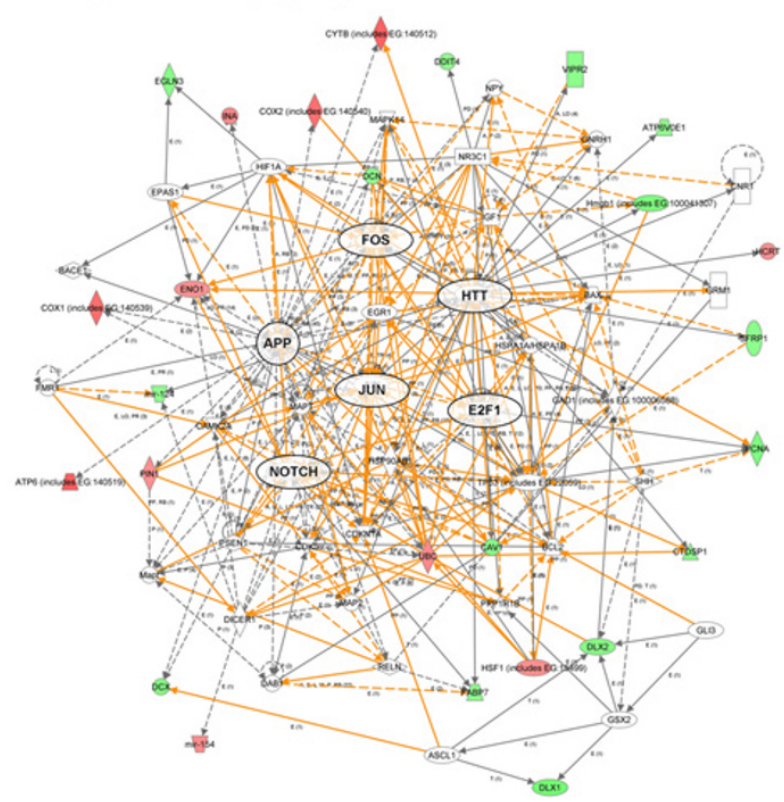

B. Neurological disease, Cell death, Psychological disorders

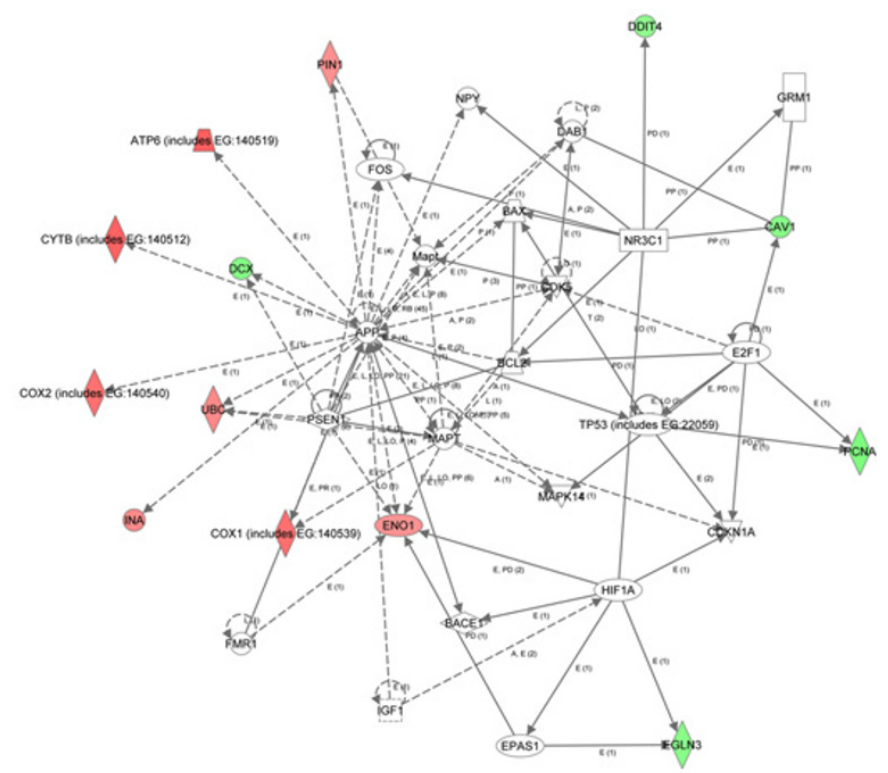

Figure 5 Ingenuity pathway analysis (IPA) network analysis indicating annotated interactions between genes affected in the adult brain by ethanol exposure at E14 and 16. Up- (red) and down- (green) regulated genes are indicated. Significant networks identified, as well as their IPA functional category, are shown in (A) and (B). (C) Merged image of networks shown in (A) and (B) showing the interrelatedness of the genes involved. Centralized 'hub' molecules linking multiple interacting genes are enlarged.

Genes that remain altered by neurodevelopmental alcohol exposure may reflect predominant biological processes occurring at the time of exposure

The results included in Table 1 and Figure 2 show that only a small number of genes were altered by ethanol by multiple treatment models. In general, these genes represent pleiotropically-acting molecules associated with cell death, regulation of gene expression, and, interestingly, methylation. Such results may argue that the most common and timing-independent response to alcohol is cellular stress, potentially leading to apoptosis at the time of exposure. The long-term changes to these genes may suggest that the surviving cells retain a 'memory' of exposure and may show altered response to subsequent 

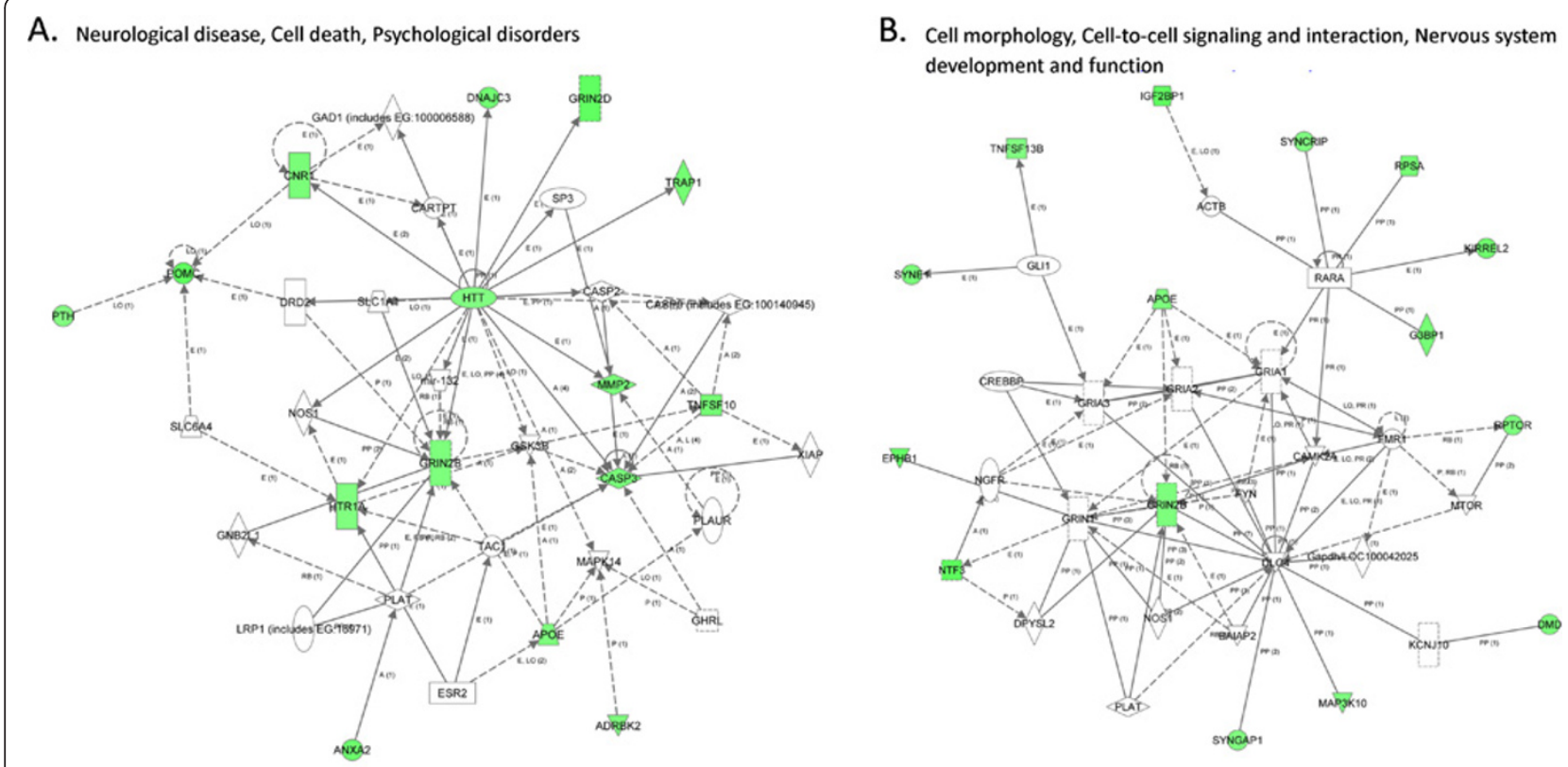

C. Merged networks highlighting central hub molecules
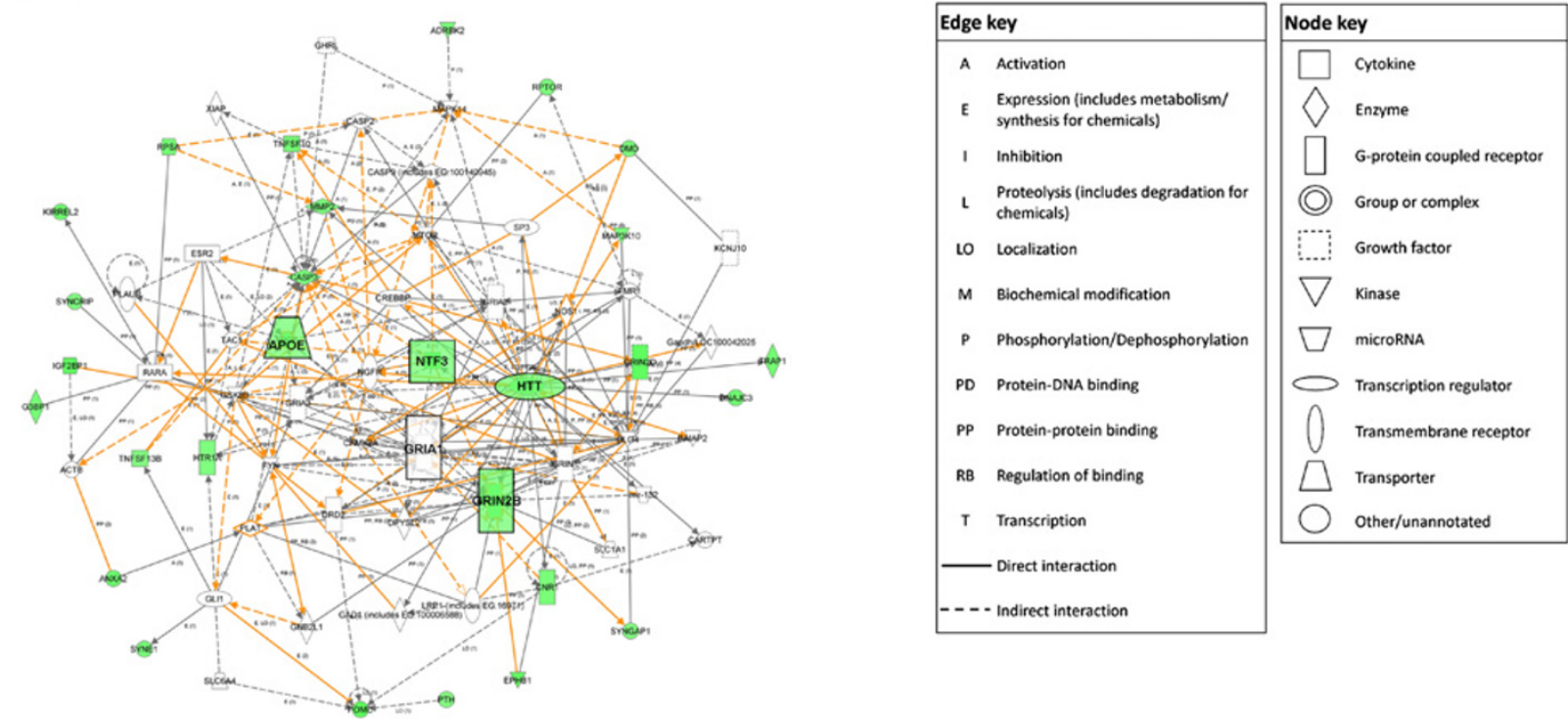

Figure 6 Ingenuity pathway analysis (IPA) network analysis indicating annotated interactions between genes affected in the adult brain by ethanol exposure at P4 and P7. Up- (red) and down- (green) regulated genes are indicated. Significant networks identified, as well as their IPA functional category, are shown in (A) and (B). (C) Merged image of networks shown in (A) and (B) showing the interrelatedness of the genes involved. Centralized 'hub' molecules linking multiple interacting genes are enlarged.

exposures. This is supported by evidence that prenatal ethanol exposure can result in heightened 'sensitization' of adult neurons to ethanol $[43,44]$, which may be a contributing factor to fetal alcohol exposure and increased risk for alcohol abuse [45]. These genes, however, represent only a small proportion of the genes detected, which suggests that the effect of developmental alcohol exposure may be dictated by the interaction between ethanol and the specific biological processes occurring at the time of exposure.

\section{Ethanol exposure during trimester one alters genes associated with tissue morphology}

We performed GO analysis on the gene lists generated by each treatment model (E8/11, E14/16, and P4/7) in order to identify the overrepresented biological functions 
altered in each paradigm. Interestingly, genes affected in each of the three treatments showed relevance to predominant biological processes occurring at the developmental stage of exposure. For example, E8/11 exposure was associated with alterations to genes involved in cellular assembly, proliferation, differentiation, cell death, and tissue morphology (Table 2), even in the adult brain. Developmentally, ethanol-induced disruptions in decisions regarding the 'accumulation of cells' and 'quantity of interneurons' during early gestation could lead to alterations in the number of cells that exist in certain brain regions, perhaps through inhibition of mitosis or by promoting inappropriate apoptosis, but it is unclear what effect the alteration of these genes may have in the adult brain. The significant functions annotations for trimester one exposure appear to be driven primarily by the altered expression of Neurotrophin 3 (Ntf3). Disruptions in Ntf3 expression during development are detrimental given its canonical role as a neuronal survival factor $[46,47]$ and regulator of axonal growth and guidance, synaptic structure, and synaptic plasticity [48-51]. In addition to having developmental roles, reduced $N t f 3$ expression in the adult brain has been shown to be associated with deficits in spatial learning, long-term potentiation impairments, and increased anxiety-related traits [52-54]. Canonical pathways analysis indicated alterations to genes involved in endoplasmic reticulum (ER) stress response and such as the downregulation of DnaJ (Hsp40) homolog, subfamily C, member 3 (Dnajc3), also known as p58IPK. Cells showing decreased expression of this molecular chaperone protein are more prone to ER stress-induced apoptosis [55,56]. These results suggest that, beyond inducing cell death upon immediate exposure, early gestational ethanol treatment may lead to increased cellular vulnerability to other insults in surviving adult neurons.

\section{Ethanol exposure during trimester two affects genes involved in cellular differentiation and migration}

In contrast to E8/11 exposure, GO analysis of genes affected by ethanol treatment at E14/16 revealed the alteration of genes developmentally involved with cell migration, differentiation, and morphology (Table 2), processes that occur rapidly during this developmental stage in many brain regions $[20,39,57]$. Physiologically, ethanol exposure during trimester two has been associated with abnormal cell division and increased the appearance of radial-glialike precursors which dictate neural stem cell migration from the ventricular zone (VZ) to the subventricular zone (SVZ) during early differentiation $[58,59]$. This leads to the depletion of certain susceptible cell types in the VZ and a corresponding abnormal increase of cells in the SVZ and may lead to the cortical heterotopias associated with FASD. Interestingly, the homeobox transcription factors distal-less homeobox 1 and $2(D l x 1$ and $D l x 2)$ as well as doublecortin $(D c x)$ were identified as altered in the adult brain following E14/16 exposure. Dcx has been previously implicated in alcohol's effects on both the developing and the adult brain [60-62], while $D l x 1$ and $D l x 2$ are the earliest $D l x$ genes to be expressed in the SVZ and are critical regulators of interneuron differentiation and migration in the developing telencephalon [63-65]. They are also responsible for the majority of GABAergic neurons in the mammalian neocortex and are therefore crucial for the regulation of the development of inhibitory neocortical circuitry [66,67]. IPA canonical pathway analysis also associated E14/16 exposure with changes to genes involved in serotonin signaling (Table 3). Indeed, three serotonin receptor subunits were identified as altered: 5-hydroxytryptamine (serotonin) receptor 5A (Htr5a), Htr3a, and Htr6. Reduced density of serotonin neurons have been previously associated with prenatal alcohol exposure [68-70]. Further, low serotonin signaling, including that caused by neurodevelopmental alcohol exposure, has been implicated in a number of phenotypic outcomes relevant to FASD such as increased impulsivity, aggression, hopelessness, exploratory activity, and risk for stress and anxiety-related traits due to altered hypothalamic-pituitary-adrenal axis function [71-75].

\section{Early postnatal ethanol exposure altered genes associated with synaptic function in the adult brain}

Spanning approximately the first 2 weeks of postnatal mouse development, the 'brain growth spurt' is a period of extensive synaptogenesis and growth within the cortex, hippocampus, and corpus callosum $[18,20]$. This stage of development, equivalent to approximately the third trimester of human neurodevelopment $[18,19]$, determines much of the extent of the brain's neural circuitry, including the maintenance or pruning of synaptic connectivity in multiple brain regions. Disruptions to these processes, such as by ethanol, may result in inappropriate synapse formation and interfere with synaptic transmission, potentiation, and plasticity in adulthood [76-79]. GO analysis of P4/7 ethanol exposure suggested that many genes altered in the adult brain by this treatment model were involved in biological processes relevant to synaptic function. A number of glutamate receptor subunits were identified, known to be critical in the formation and maintenance of synapses, synaptic plasticity, and long-term potentiation (LTP) [80-85]. Also of note is the downregulation of Eph receptor B1 and B2 (Ephb1 and Ephb2), known to have classic functions in axon guidance and brain region boundary formation [86] as well as potentially controlling many other aspects of excitatory synaptic transmission and plasticity [87-89]. Interestingly, ethanol exposure at $\mathrm{P} 4 / 7$ also resulted in altered steroid secretion due to the downregulation of both apolipoprotein E (Apoe) and proopiomelanocortin (Pomc), molecules that are essential for proper hypothalamic-pituitary 
-adrenal (HPA) axis function. Apoe deficiency is associated with age-related neurodegeneration and cognitive decline [90,91]. Phenotypically, Apoe null mice show increased anxiety in the elevated plus maze but reduced activity in a novel open field environment, which coincides with increased plasma corticosterone levels and impaired performance in spatial learning tests [90,92]. Contrastingly, Pomc has been shown to be essential for postnatal adrenal maturation, with Pomc null mice showing no production of corticosterone [93]. Given this, it is certainly possible that long-term alterations in the expression of these genes may contribute to phenotypes such as cognitive abnormalities and increased stress reactivity observed individuals with FASD. The IPA canonical pathway analysis reflected the results of the GO analysis, with genes associated with glutamate receptor signaling and ephrin receptor significantly represented. Genes associated with retinoic acidmediated apoptosis signaling were also altered, a finding which is supported by other studies that report that prenatal ethanol exposure can lower retinoic ethanol receptor function and elevate retinoic acid levels beyond normal physiological levels [94-96]. Folate metabolism has also been implicated in FASD phenotypes as folic acid supplementation has been shown to ameliorate some of the effects of prenatal alcohol consumption [97,98]. Finally, although it is known that the hypothalamus, including the control of circadian 'clock genes', is disrupted by neurodevelopmental alcohol exposure $[14,99,100]$, the identification of circadian rhythm signaling is interesting given that disturbed sleep patterns is a reported but relatively unexplored consequence of fetal alcohol exposure. This may be due to the disruption of corticotrophin-releasing hormone neurotransmission due to abnormal synaptic tract formation, but this potential consequence associated with trimester three ethanol exposure requires further investigation.

\section{Common molecular pathways may mediate the effect of ethanol on neurodevelopment despite execution through trimester-specific gene sets}

As a final part of this study, we conducted IPA network analysis initially to evaluate further differences to adult brain gene expression following ethanol treatment at various neurodevelopmental stages. Evaluation of these gene sets, however, revealed numerous similarities between gene networks. While each treatment was associated with somewhat different significant IPA networks, the merged gene networks for each model revealed similar sets of gene 'hubs' (Figures 4, 5, and 6). While these 'hubs' were not necessarily altered themselves, they linked dysregulated genes suggesting that there may be some common processes that remain altered into adulthood following developmental ethanol exposure, regardless of timing. Specifically, glutamate receptor subunits appeared as core molecules in all treatment paradigms, as did many neurotrophic molecules. Also, the developmentally-essential gene $H t t$ was associated with the altered gene networks of each ethanol treatment model. This is, as far as we are aware, unreported in prenatal alcohol exposure literature; however, it is known that $\mathrm{Htt}$ has roles in cell survival, proliferation, and migration [101,102]. Further, wild-type Htt binds repressor proteins allowing the expression of critical neuronal genes such as BDNF [103]. Despite this and its well-established role in neuropathology, its relationship with neurodevelopmental alcohol exposure remains an unexplored avenue, and though its consistent appearance as a hub here is intriguing, an explanation would only be speculative.

\section{Neurodevelopmental ethanol exposure and long-term gene expression changes}

Given that this study examined the long-term effects of neurodevelopmental exposure to ethanol, it may be pertinent to ask what initiates and maintains these gene expression changes over time. A clear answer to these questions is not straightforward and may involve some combination of the primary (acute) and secondary effects of ethanol exposure. Factors that instigate these changes in gene expression may include ethanol-induced apoptosis of susceptible cell types, leading to an overall change in the cellular composition of the brain and, subsequently, the overall pattern of brain gene expression $[27,32]$. The authors acknowledge that the use of whole brain tissue makes this a possible reason for the results obtained by this study. Also, it is important to note that, while the genes identified may represent a broad response by the neural transcriptome to ethanol, it would be expected that various brain regions respond differently to ethanol exposure given that developmental processes do not occur uniformly and each region would have its own gene expression profile.

Another contributing mechanism may be the ability of ethanol to disrupt developmental processes that are highly reliant on external cues such as cell proliferation, migration, or differentiation $[39,58,104]$. These mechanisms would represent immediate effects of alcohol that, during adulthood, do not directly alter gene expression per se but have altered cellular identity or physiology of the brain such that the appropriate balance of neural gene expression is not maintained. This hypothesis has been suggested for a number of spectrum disorders, and has been referred to as a neurodevelopmental 'footprint' of teratogen exposure $[15,105,106]$.

Finally, it is possible that there may be some factors that maintain inappropriate gene expression at the molecular level. Recent reports suggest that developmental ethanol exposure can affect epigenetic patterning, particularly DNA methylation and microRNA expression, which can produce 
long-term and relatively stable changes to the expression of a number of genes [107-111]. How these changes may occur and how they are maintained is unknown, but this hypothesis is certainly worth further investigating as it would have implications towards the persistence of FASD phenotypes throughout the life of an individual.

\section{Conclusions}

This study was initiated to provide a comparison of the timing effects of neurodevelopmental ethanol exposure on long-term changes in the brain transcriptome. The results show that ethanol causes long-term molecular changes at all developmental stages studied. Also, ethanol treatment, regardless of timing, appears to cause a long-term disruption to genes associated with developmental processes that are active at the time of exposure, resulting in a molecular 'footprint' of altered genes that perhaps reflects the most susceptible biological networks at that developmental stage. This disruption likely influences the resulting physiology of the adolescent and adult brain and, subsequently, the phenotypes observed in the exposed individual. Not only does this argue that timing is an important factor in determining the variability and severity of FASD-related traits, but also that knowledge of the developmental stage of exposure may offer a modest predictive value towards the cognitive and behavioral outcomes of an individual prenatally exposed to alcohol. While future experiments are needed to assess the mechanisms underlying the observed gene expression changes, including differences between distinct brain regions and cell types, this model may provide an opportunity to evaluate some of the molecular processes that suffer long-term changes from alcohol exposure at susceptible neurodevelopmental times.

\section{Additional file}

Additional file 1: Table S1. Genes identified as differentially expressed in the brain of adult mice following neurodevelopmental alcohol exposure. Lists represent genes identified at P60 following ethanol treatment at E8/11 (trimester 1), E14/16 (trimester 2), and P4/7 (trimester 3). Data included are gene-specific fold-changes and $P$-values.

\section{Competing interests}

The authors declare that they have no competing interests.

\section{Authors' contributions}

MLK and KM performed all mouse work including injections and tissue isolation. RNA extraction was performed by MLK, KM, and RLS. KM performed mouse work, tissue isolation and extractions for trimesters 1 and 2. MLK performed all array and pathway analyses. Gene confirmation was performed by MLK, KM, and RLS. Manuscript was written by MLK with contributions from KM and SMS. Project was developed by MLK, KM, and SMS. All authors read and approved the final manuscript.

\section{Acknowledgements}

This work was supported by funding from the Queen Elizabeth II Scholarship in Science and Technology (QEIISST) to MLK and grants from the Natural Sciences and Engineering Research Council of Canada (NSERC), Canadian Institutes of Health Research (CIHR), and the Ontario Mental Health
Foundation (OMHF) to SMS. The authors thank David Carter and the Robarts Research Institute for their assistance and expertise with array hybridization.

Received: 2 November 2012 Accepted: 20 February 2013

Published: 13 March 2013

\section{References}

1. Chudley AE, Conry J, Cook JL, Loock C, Rosales T, LeBlanc N: Fetal alcohol spectrum disorder: Canadian guidelines for diagnosis. CMAJ 2005, 172:S1-S21.

2. Rasmussen C: Executive functioning and working memory in fetal alcohol spectrum disorder. Alcohol Clin Exp Res 2005, 29:1359-1367.

3. Streissguth AP, O'Malley K: Neuropsychiatric implications and long-term consequences of fetal alcohol spectrum disorders. Semin Clin Neuropsychiatry 2000, 5:177-190.

4. Marchetta CM, Denny CH, Floyd RL, Cheal NE, Sniezek JE: Alcohol use and binge drinking among women of childbearing age-United States, 2006-2010. MMWR Morb Mortal Wkly Rep 2012, 61:534-538.

5. Bertrand J, Floyd LL, Weber MK: Guidelines for identifying and referring persons with fetal alcohol syndrome. MMWR Recomm Rep 2005, 54:1-14.

6. Lupton C, Burd L, Harwood R: Cost of fetal alcohol spectrum disorders. Am J Med Genet C Semin Med Genet 2004, 127C:42-50.

7. Stade B, Ali A, Bennett D, Campbell D, Johnston M, Lens C, Tran S, Koren G: The burden of prenatal exposure to alcohol: revised measurement of cost. Can J Clin Pharmacol 2009, 16:e91-102.

8. Fast DK, Conry J: The challenge of fetal alcohol syndrome in the criminal legal system. Addict Biol 2004, 9:161-166. discussion 167-8.

9. Famy C, Streissguth AP, Unis AS: Mental illness in adults with fetal alcohol syndrome or fetal alcohol effects. Am J Psychiatry 1998, 155:552-554.

10. Nash K, Sheard E, Rovet J, Koren G: Understanding fetal alcohol spectrum disorders (FASDs): toward identification of a behavioral phenotype. ScientificWorldJournal 2008, 8:873-882.

11. Green ML, Singh AV, Zhang $Y$, Nemeth KA, Sulik KK, Knudsen TB: Reprogramming of genetic networks during initiation of the Fetal Alcohol Syndrome. Dev Dyn 2007, 236:613-631.

12. Hard ML, Abdolell M, Robinson BH, Koren G: Gene-expression analysis after alcohol exposure in the developing mouse. J Lab Clin Med 2005, 145:47-54.

13. Zhou FC, Zhao Q, Liu Y, Goodlett CR, Liang T, McClintick JN, Edenberg HJ, $\mathrm{Li}$ L: Alteration of gene expression by alcohol exposure at early neurulation. BMC Genomics 2011, 12:124.

14. Chen CP, Kuhn P, Advis JP, Sarkar DK: Prenatal ethanol exposure alters the expression of period genes governing the circadian function of beta-endorphin neurons in the hypothalamus. J Neurochem 2006, 97:1026-1033.

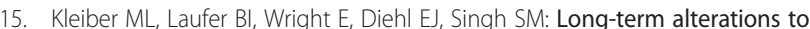
the brain transcriptome in a maternal voluntary consumption model of fetal alcohol spectrum disorders. Brain Res 2012, 1458:18-33.

16. Toso L, Poggi SH, Abebe D, Roberson R, Dunlap V, Park J, Spong CY: $\mathrm{N}$-methyl-D-aspartate subunit expression during mouse development altered by in utero alcohol exposure. Am J Obstet Gynecol 2005, 193:1534-1539.

17. Toso L, Roberson R, Woodard J, Abebe D, Spong CY: Prenatal alcohol exposure alters GABA(A)alpha5 expression: a mechanism of alcoholinduced learning dysfunction. Am J Obstet Gynecol 2006, 195:522-527.

18. Clancy B, Darlington RB, Finlay BL: Translating developmental time across mammalian species. Neuroscience 2001, 105:7-17.

19. Dobbing J, Sands J: Comparative aspects of the brain growth spurt. Early Hum Dev 1979, 3:79-83.

20. Dobbing J, Sands J: Quantitative growth and development of human brain. Arch Dis Child 1973, 48:757-67.

21. Mantha K, Kleiber ML, Singh SM: Neurodevelopmental timing of ethanol exposure may contribute to observed heterogeneity of behavioural deficits in a mouse model of Fetal Alcohol Spectrum Disorder (FASD) J Behav Brain Sci 2013, 3:85-99.

22. Hunt PS, Jacobson SE, Torok EJ: Deficits in trace fear conditioning in a rat model of fetal alcohol exposure: dose-response and timing effects. Alcohol 2009, 43:465-474.

23. Lipinski RJ, Hammond P, O'Leary-Moore SK, Ament JJ, Pecevich SJ, Jiang Y, Budin F, Parnell SE, Suttie M, Godin EA, Everson JL, Dehart DB, Oguz I, Holloway HT, Styner MA, Johnson GA, Sulik KK: Ethanol-induced face-brain 
dysmorphology patterns are correlative and exposure-stage dependent. PLoS One 2012, 7:e43067.

24. Barr HM, Bookstein FL, O'Malley KD, Connor PD, Huggins JE, Streissguth AP: Binge drinking during pregnancy as a predictor of psychiatric disorders on the Structured Clinical Interview for DSM-IV in young adult offspring. Am J Psychiatry 2006, 163:1061-1065.

25. Schlessinger AR, Cowan WM, Gottlieb DI: An autoradiographic study of the time of origin and the pattern of granule cell migration in the dentate gyrus of the rat. J Comp Neurol 1975, 159:149-175.

26. Wozniak DF, Hartman RE, Boyle MP, Vogt SK, Brooks AR, Tenkova T, Young C, Olney JW, Muglia L: Apoptotic neurodegeneration induced by ethanol in neonatal mice is associated with profound learning/memory deficits in juveniles followed by progressive functional recovery in adults. Neurobiol Dis 2004, 17:403-414.

27. Ikonomidou C, Bittigau P, Ishimaru MJ, Wozniak DF, Koch C, Genz K, Price MT, Stefovska V, Horster F, Tenkova T, Dikranian K, Olney JW: Ethanolinduced apoptotic neurodegeneration and fetal alcohol syndrome. Science 2000, 287:1056-1060.

28. Irizarry RA, Bolstad BM, Collin F, Cope LM, Hobbs B, Speed TP: Summaries of Affymetrix GeneChip probe level data. Nucleic Acids Res 2003, 31:e15.

29. Dennis G Jr, Sherman BT, Hosack DA, Yang J, Gao W, Lane HC, Lempicki RA: DAVID: Database for Annotation, Visualization, and Integrated Discovery. Genome Biol 2003, 4:P3.

30. da Huang W, Sherman BT, Lempicki RA: Bioinformatics enrichment tools: paths toward the comprehensive functional analysis of large gene lists. Nucleic Acids Res 2009, 37:1-13.

31. Schmittgen TD, Livak KJ: Analyzing real-time PCR data by the comparative C(T) method. Nat Protoc 2008, 3:1101-1108

32. Olney JW, Tenkova T, Dikranian K, Qin YQ, Labruyere J, Ikonomidou C: Ethanol-induced apoptotic neurodegeneration in the developing C57BL/ 6 mouse brain. Brain Res Dev Brain Res 2002, 133:115-126.

33. Young C, Olney JW: Neuroapoptosis in the infant mouse brain triggered by a transient small increase in blood alcohol concentration. Neurobiol Dis 2006, 22:548-554.

34. Fagerlund A, Heikkinen S, Autti-Ramo I, Korkman M, Timonen M, Kuusi T, Riley EP, Lundbom N: Brain metabolic alterations in adolescents and young adults with fetal alcohol spectrum disorders. Alcohol Clin Exp Res 2006, 30:2097-2104

35. Jirikowic T, Olson HC, Kartin D: Sensory processing, school performance, and adaptive behavior of young school-age children with fetal alcohol spectrum disorders. Phys Occup Ther Pediatr 2008, 28:117-136.

36. Stade B, Beyene J, Buller K, Ross S, Patterson K, Stevens B, Sgro M, Ungar W, Watson W, Koren G: Feeling different: the experience of living with fetal alcohol spectrum disorder. J Popul Ther Clin Pharmacol 2011, 18:e475-485.

37. Dobbing J: The later growth of the brain and its vulnerability. Pediatrics 1974, 53:2-6.

38. Blakley PM, Scott WJ Jr: Determination of the proximate teratogen of the mouse fetal alcohol syndrome. 2. Pharmacokinetics of the placental transfer of ethanol and acetaldehyde. Toxicol Appl Pharmacol 1984, 72:364-371.

39. Rice D, Barone $\mathrm{S} \mathrm{Jr}$ : Critical periods of vulnerability for the developing nervous system: evidence from humans and animal models. Environ Health Perspect 2000, Suppl 3:511-533.

40. Allan AM, Chynoweth J, Tyler LA, Caldwell KK: A mouse model of prenatal ethanol exposure using a voluntary drinking paradigm. Alcohol Clin Exp Res 2003, 27:2009-2016.

41. Kleiber ML, Wright E, Singh SM: Maternal voluntary drinking in C57BL/6J mice: Advancing a model for fetal alcohol spectrum disorders. Behav Brain Res 2011, 223:376-387.

42. McMurray MS, Williams SK, Jarrett TM, Cox ET, Fay EE, Overstreet DH, Walker $\mathrm{CH}$, Johns JM: Gestational ethanol and nicotine exposure: effects on maternal behavior, oxytocin, and offspring ethanol intake in the rat. Neurotoxicol Teratol 2008, 30:475-486.

43. Chang GQ, Karatayev O, Liang SC, Barson JR, Leibowitz SF: Prenatal ethanol exposure stimulates neurogenesis in hypothalamic and limbic peptide systems: possible mechanism for offspring ethanol overconsumption. Neuroscience 2012, 222:417-428.

44. Dubois C, Naassila M, Daoust M, Pierrefiche O: Early chronic ethanol exposure in rats disturbs respiratory network activity and increases sensitivity to ethanol. J Physiol 2006, 576:297-307.
45. Alati R, Al Mamun A, Williams GM, O'Callaghan M, Najman JM, Bor W: In utero alcohol exposure and prediction of alcohol disorders in early adulthood: a birth cohort study. Arch Gen Psychiatry 2006, 63:1009-1016.

46. Barde YA: Trophic factors and neuronal survival. Neuron 1989, 2:1525-1534.

47. Kirstein M, Farinas I: Sensing life: regulation of sensory neuron survival by neurotrophins. Cell Mol Life Sci 2002, 59:1787-1802.

48. Genc B, Ozdinler PH, Mendoza AE, Erzurumlu RS: A chemoattractant role for NT-3 in proprioceptive axon quidance. PLoS Biol 2004, 2:e403.

49. Je HS, Zhou J, Yang F, Lu B: Distinct mechanisms for neurotrophin-3-induced acute and long-term synaptic potentiation. J Neurosci 2005, 25:11719-11729.

50. Chao MV: Neurotrophins and their receptors: a convergence point for many signalling pathways. Nat Rev Neurosci 2003, 4:299-309.

51. Lykissas MG, Batistatou AK, Charalabopoulos KA, Beris AE: The role of neurotrophins in axonal growth, guidance, and regeneration. Curr Neurovasc Res 2007, 4:143-151.

52. Uys JD, Marais L, Faure J, Prevoo D, Swart P, Mohammed AH, Stein DJ, Daniels WM: Developmental trauma is associated with behavioral hyperarousal, altered HPA axis activity, and decreased hippocampal neurotrophin expression in the adult rat. Ann N Y Acad Sci 2006, 1071:542-546.

53. Reus GZ, Stringari RB, Ribeiro KF, Cipriano AL, Panizzutti BS, Stertz L, Lersch C, Kapczinski F, Quevedo J: Maternal deprivation induces depressive-like behaviour and alters neurotrophin levels in the rat brain. Neurochem Res 2011, 36:460-466.

54. Shimazu K, Zhao M, Sakata K, Akbarian S, Bates B, Jaenisch R, Lu B: NT-3 facilitates hippocampal plasticity and learning and memory by regulating neurogenesis. Learn Mem 2006, 13:307-315.

55. Zhao L, Rosales C, Seburn K, Ron D, Ackerman SL: Alteration of the unfolded protein response modifies neurodegeneration in a mouse model of Marinesco-Sjogren syndrome. Hum Mol Genet 2010, 19:25-35.

56. Yan W, Frank CL, Korth MJ, Sopher BL, Novoa I, Ron D, Katze MG: Control of PERK elF2alpha kinase activity by the endoplasmic reticulum stressinduced molecular chaperone P58IPK. Proc Natl Acad Sci U S A 2002, 99:15920-15925.

57. Singer HS, Chiu AY, Meiri KF, Morell P, Nelson PG, Tennekoon G: Advances in understanding the development of the nervous system. Curr Opin Neurol 1994, 7:153-159

58. Camarillo C, Miranda RC: Ethanol exposure during neurogenesis induces persistent effects on neural maturation: evidence from an ex vivo model of fetal cerebral cortical neuroepithelial progenitor maturation. Gene Expr 2008, 14:159-171.

59. Hansen DV, Lui JH, Parker PR, Kriegstein AR: Neurogenic radial glia in the outer subventricular zone of human neocortex. Nature 2010 464:554-561.

60. Stevenson JR, Schroeder JP, Nixon K, Besheer J, Crews FT, Hodge CW: Abstinence following alcohol drinking produces depression-like behavior and reduced hippocampal neurogenesis in mice. Neuropsychopharmacology 2009, 34:1209-1222.

61. He J, Nixon K, Shetty AK, Crews FT: Chronic alcohol exposure reduces hippocampal neurogenesis and dendritic growth of newborn neurons. Eur J Neurosci 2005, 21:2711-2720.

62. Hansson AC, Nixon K, Rimondini R, Damadzic R, Sommer WH, Eskay R, Crews FT, Heilig M: Long-term suppression of forebrain neurogenesis and loss of neuronal progenitor cells following prolonged alcohol dependence in rats. Int I Neuropsychopharmacol 2010, 13:583-593.

63. Eisenstat DD, Liu JK, Mione M, Zhong W, Yu G, Anderson SA, Ghattas I, Puelles L, Rubenstein JL: DLX-1, DLX-2, and DLX-5 expression define distinct stages of basal forebrain differentiation. J Comp Neurol 1999, 414:217-237.

64. Liu JK, Ghattas I, Liu S, Chen S, Rubenstein JL: Dlx genes encode DNA-binding proteins that are expressed in an overlapping and sequential pattern during basal ganglia differentiation. Dev Dyn 1997, 210:498-512.

65. Ghanem N, Andrusiak MG, Svoboda D, Al Lafi SM, Julian LM, McClellan KA, De Repentigny Y, Kothary R, Ekker M, Blais A, Park DS, Slack RS: The Rb/E2F pathway modulates neurogenesis through direct regulation of the Dlx1/ Dlx2 bigene cluster. J Neurosci 2012, 32:8219-8230.

66. Jones DL, Howard MA, Stanco A, Rubenstein JL, Baraban SC: Deletion of Dlx1 results in reduced glutamatergic input to hippocampal interneurons. J Neurophysiol 2011, 105:1984-1991.

67. Letinic K, Zoncu R, Rakic P: Origin of GABAergic neurons in the human neocortex. Nature 2002, 417:645-649. 
68. Tajuddin NF, Druse MJ: In utero ethanol exposure decreased the density of serotonin neurons. Maternal ipsapirone treatment exerted a protective effect. Brain Res Dev Brain Res 1999, 117:191-197.

69. Schneider ML, Moore CF, Barr CS, Larson JA, Kraemer GW: Moderate prenatal alcohol exposure and serotonin genotype interact to alter CNS serotonin function in rhesus monkey offspring. Alcohol Clin Exp Res 2011, 35:912-920

70. Sari $Y$, Zhou FC: Prenatal alcohol exposure causes long-term serotonin neuron deficit in mice. Alcohol Clin Exp Res 2004, 28:941-948.

71. Hofmann CE, Ellis L, Yu WK, Weinberg J: Hypothalamic-pituitary-adrenal responses to 5-HT1A and 5-HT2A/C agonists are differentially altered in female and male rats prenatally exposed to ethanol. Alcohol Clin Exp Res 2007, 31:345-355.

72. Grailhe R, Waeber C, Dulawa SC, Hornung JP, Zhuang X, Brunner D, Geyer $M A$, Hen R: Increased exploratory activity and altered response to LSD in mice lacking the 5-HT(5A) receptor. Neuron 1999, 22:581-591.

73. Caspi A, Sugden K, Moffitt TE, Taylor A, Craig IW, Harrington H, McClay J, Mill J, Martin J, Braithwaite A, Poulton R: Influence of life stress on depression: moderation by a polymorphism in the 5 - $\mathrm{HTT}$ gene. Science 2003, 301:386-389.

74. Higley JD, Linnoila M: Low central nervous system serotonergic activity is traitlike and correlates with impulsive behavior. A nonhuman primate model investigating genetic and environmental influences on neurotransmission. Ann N Y Acad Sci 1997, 836:39-56.

75. Mehlman PT, Higley JD, Faucher I, Lilly AA, Taub DM, Vickers J, Suomi SJ, Linnoila M: Low CSF 5-HIAA concentrations and severe aggression and impaired impulse control in nonhuman primates. Am J Psychiatry 1994, 151:1485-1491.

76. Olney JW, Wozniak DF, Farber NB, Jevtovic-Todorovic V, Bittigau P, Ikonomidou C: The enigma of fetal alcohol neurotoxicity. Ann Med 2002, 34:109-119.

77. Mameli M, Zamudio PA, Carta M, Valenzuela CF: Developmentally regulated actions of alcohol on hippocampal glutamatergic transmission. J Neurosci 2005, 25:8027-8036.

78. Puglia MP, Valenzuela CF: Ethanol acutely inhibits ionotropic glutamate receptor-mediated responses and long-term potentiation in the developing CA1 hippocampus. Alcohol Clin Exp Res 2010, 34:594-606.

79. Servais L, Hourez R, Bearzatto B, Gall D, Schiffmann SN, Cheron G: Purkinje cell dysfunction and alteration of long-term synaptic plasticity in fetal alcohol syndrome. Proc Natl Acad Sci U S A 2007, 104:9858-9863.

80. Kim MH, Choi J, Yang J, Chung W, Kim JH, Paik SK, Kim K, Han S, Won H, Bae YS, Cho SH, Seo J, Bae YC, Choi SY, Kim E: Enhanced NMDA receptormediated synaptic transmission, enhanced long-term potentiation, and impaired learning and memory in mice lacking IRSp53. J Neurosci 2009, 29:1586-1595.

81. Cotman CW, Monaghan DT, Ganong AH: Excitatory amino acid neurotransmission: NMDA receptors and Hebb-type synaptic plasticity. Annu Rev Neurosci 1988, 11:61-80.

82. Rabacchi S, Bailly Y, Delhaye-Bouchaud N, Mariani J: Involvement of the Nmethyl D-aspartate (NMDA) receptor in synapse elimination during cerebellar development. Science 1992, 256:1823-1825.

83. Luthi A, Schwyzer L, Mateos JM, Gahwiler BH, McKinney RA: NMDA receptor activation limits the number of synaptic connections during hippocampal development. Nat Neurosci 2001, 4:1102-1107.

84. Gambrill AC, Barria A: NMDA receptor subunit composition controls synaptogenesis and synapse stabilization. Proc Natl Acad Sci U S A 2011, 108:5855-5860.

85. Liu L, Wong TP, Pozza MF, Lingenhoehl K, Wang Y, Sheng M, Auberson YP, Wang YT: Role of NMDA receptor subtypes in governing the direction of hippocampal synaptic plasticity. Science 2004 304:1021-1024.

86. Kullander K, Klein R: Mechanisms and functions of Eph and ephrin signalling. Nat Rev Mol Cell Biol 2002, 3:475-486.

87. Dalva MB, Takasu MA, Lin MZ, Shamah SM, Hu L, Gale NW, Greenberg ME: EphB receptors interact with NMDA receptors and regulate excitatory synapse formation. Cell 2000, 103:945-956.

88. Henkemeyer M, Itkis OS, Ngo M, Hickmott PW, Ethell IM: Multiple EphB receptor tyrosine kinases shape dendritic spines in the hippocampus. J Cell Biol 2003, 163:1313-1326.
89. Henderson JT, Georgiou J, Jia Z, Robertson J, Elowe S, Roder JC, Pawson T: The receptor tyrosine kinase EphB2 regulates NMDA-dependent synaptic function. Neuron 2001, 32:1041-1056.

90. Grootendorst J, Kempes MM, Lucassen PJ, Dalm S, de Kloet ER, Oitzl MS Differential effect of corticosterone on spatial learning abilities in apolipoprotein E knockout and C57BL/6J mice. Brain Res 2002, 953:281-285.

91. Masliah E, Mallory M, Ge N, Alford M, Veinbergs I, Roses AD: Neurodegeneration in the central nervous system of apoE-deficient mice. Exp Neurol 1995, 136:107-122

92. Raber J, Akana SF, Bhatnagar S, Dallman MF, Wong D, Mucke L: Hypothalamic-pituitary-adrenal dysfunction in Apoe(-/-) mice: possible role in behavioral and metabolic alterations. J Neurosci 2000, 20:2064-2071.

93. Karpac J, Ostwald D, Bui S, Hunnewell P, Shankar M, Hochgeschwender U: Development, maintenance, and function of the adrenal gland in early postnatal proopiomelanocortin-null mutant mice. Endocrinology 2005, 146:2555-2562.

94. Kane MA, Folias AE, Wang C, Napoli JL: Ethanol elevates physiological all-trans-retinoic acid levels in select loci through altering retinoid metabolism in multiple loci: a potential mechanism of ethanol toxicity. FASEB J 2010, 24:823-832.

95. Kumar A, Singh CK, DiPette DD, Singh US: Ethanol impairs activation of retinoic acid receptors in cerebellar granule cells in a rodent model of fetal alcohol spectrum disorders. Alcohol Clin Exp Res 2010, 34:928-937.

96. Grummer MA, Zachman RD: Prenatal ethanol consumption alters the expression of cellular retinol binding protein and retinoic acid receptor mRNA in fetal rat embryo and brain. Alcohol Clin Exp Res 1995, 19:1376-1381.

97. Xu Y, Tang Y, Li Y: Effect of folic acid on prenatal alcohol-induced modification of brain proteome in mice. Br J Nutr 2008, 99:455-461.

98. Wang LL, Zhang Z, Li Q, Yang R, Pei X, Xu Y, Wang J, Zhou SF, Li Y: Ethanol exposure induces differential microRNA and target gene expression and teratogenic effects which can be suppressed by folic acid supplementation. Hum Reprod 2009, 24:562-579.

99. Sakata-Haga H, Dominguez HD, Sei H, Fukui Y, Riley EP, Thomas JD: Alterations in circadian rhythm phase shifting ability in rats following ethanol exposure during the third trimester brain growth spurt. Alcohol Clin Exp Res 2006, 30:899-907.

100. Earnest DJ, Chen WJ, West JR: Developmental alcohol and circadian clock function. Alcohol Res Health 2001, 25:136-140.

101. Nasir J, Floresco SB, O'Kusky JR, Diewert VM, Richman JM, Zeisler J, Borowski A, Marth JD, Phillips AG, Hayden MR: Targeted disruption of the Huntington's disease gene results in embryonic lethality and behavioral and morphological changes in heterozygotes. Cell 1995, 81:811-823.

102. Tong Y, Ha TJ, Liu L, Nishimoto A, Reiner A, Goldowitz D: Spatial and temporal requirements for huntingtin $(\mathrm{Htt})$ in neuronal migration and survival during brain development. J Neurosci 2011, 31:14794-14799.

103. Zuccato C, Ciammola A, Rigamonti D, Leavitt BR, Goffredo D, Conti L, MacDonald ME, Friedlander RM, Silani V, Hayden MR, Timmusk T, Sipione S, Cattaneo E: Loss of huntingtin-mediated BDNF gene transcription in Huntington's disease. Science 2001, 293:493-498.

104. Guerri C: Neuroanatomical and neurophysiological mechanisms involved in central nervous system dysfunctions induced by prenatal alcohol exposure. Alcohol Clin Exp Res 1998, 22:304-312.

105. Demjaha A, Maccabe JH, Murray RM: How genes and environmental factors determine the different neurodevelopmental trajectories of schizophrenia and bipolar disorder. Schizophr Bull 2011, 38:209-214.

106. Dufour-Rainfray D, Vourc'h P, Tourlet S, Guilloteau D, Chalon S, Andres CR: Fetal exposure to teratogens: evidence of genes involved in autism. Neurosci Biobehav Rev 2011, 35:1254-1265.

107. Kaminen-Ahola N, Ahola A, Maga M, Mallitt KA, Fahey P, Cox TC, Whitelaw E, Chong S: Maternal ethanol consumption alters the epigenotype and the phenotype of offspring in a mouse model. PLOS Genet 2010, 6:e1000811

108. Liu Y, Balaraman Y, Wang G, Nephew KP, Zhou FC: Alcohol exposure alters DNA methylation profiles in mouse embryos at early neurulation. Epigenetics 2009, 4:500-511.

109. Sathyan P, Golden HB, Miranda RC: Competing interactions between micro-RNAs determine neural progenitor survival and proliferation after 
ethanol exposure: evidence from an ex vivo model of the fetal cerebral cortical neuroepithelium. J Neurosci 2007, 27:8546-8557.

110. Miranda RC: MicroRNAs and fetal brain development: implications for ethanol teratology during the second trimester period of neurogenesis. Front Genet 2011, 3:77.

111. Wang G, Wang X, Wang Y, Yang JY, Li L, Nephew KP, Edenberg HJ, Zhou $F C$, Liu Y: Identification of transcription factor and microRNA binding sites in responsible to fetal alcohol syndrome. BMC Genomics 2008, Suppl 1:S19.

doi:10.1186/1866-1955-5-6

Cite this article as: Kleiber et al:: Neurodevelopmental alcohol exposure elicits long-term changes to gene expression that alter distinct molecular pathways dependent on timing of exposure. Journal of Neurodevelopmental Disorders 2013 5:6.

\section{Submit your next manuscript to BioMed Central and take full advantage of:}

- Convenient online submission

- Thorough peer review

- No space constraints or color figure charges

- Immediate publication on acceptance

- Inclusion in PubMed, CAS, Scopus and Google Scholar

- Research which is freely available for redistribution 